\title{
Revalidação de Cathorops arenatus e Cathorops agassizii (Siluriformes, Ariidae), bagres marinhos das regiões norte e nordeste da América do Sul
}

\author{
Alexandre P. Marceniuk \\ Museu de Zoologia da Universidade de São Paulo, Caixa Postal 42494, CEP 04218-970 São Paulo, SP. (a_marceniuk@ @otmail.com)
}

\begin{abstract}
Nominal species from north and northeast South America, traditionally recognized in the literature as synonymous of Cathorops spixii (Agassiz, 1829), have their specific status redefined. Type specimens of Arius arenatus Valenciennes, 1840, Arius fissus Valenciennes, 1840, Tachisurus agassizii Eigenmann \& Eigenmann, 1888 and Arius pleurops Boulenger, 1897 were examined. Cathorops arenatus and Cathorops agassizii are considered valid, Cathorops fissus is a junior synonym of Cathorops arenatus and Cathorops pleurops a junior synonym of Cathorops agassizii. The morphometric characters traditionally used in descriptions and keys in the family Ariidae are redefined and new characters are used.
\end{abstract}

KEYWORDS. Taxonomic status, nominal species of Cathorops, redescription, South America.

RESUMO. As espécies nominais das regiões norte e nordeste da América do Sul, reconhecidas na literatura como sinônimos júnior de Cathorops spixii (Agassiz, 1829) têm seu status específico revisto. Os tipos de Arius arenatus Valenciennes, 1840, Arius fissus Valenciennes, 1840, Tachisurus agassizii Eigenmann \& Eigenmann, 1888 e Arius pleurops Boulenger, 1897 foram examinados. Cathorops arenatus e Cathorops agassizii são espécies válidas, Cathorops fissus é sinônimo júnior de Cathorops arenatus e Cathorops pleurops sinônimo júnior de Cathorops agassizii. Os caracteres morfométricos tradicionalmente usados em descrições e chaves de identificação para espécies da família Ariidae são redefinidos e novos caracteres são utilizados.

PALAVRAS-CHAVE. Status taxonômico, espécies nominais de Cathorops, redescrição, América do Sul.

Os bagres da família Ariidae apresentam distribuição circumglobal e habitam regiões litorâneas, estuarinas e rios costeiros de regiões tropicais e temperadas. A maioria das espécies ocorre em áreas costeiras rasas e estuários. Espécies exclusivamente marinhas podem ser encontradas em profundidades superiores a $100 \mathrm{~m}$, outras ocorrem somente em água doce.

O formato das placas de dentes e o tipo de dente presente nestas placas foram durante muito tempo as principais características utilizadas na definição de gêneros e espécies de Ariidae. A utilização destas e de outras características da morfologia externa sem o devido conhecimento da variação decorrente do desenvolvimento ontogenético e das diferenças entre os sexos geraram muitas dificuldades no correto reconhecimento dos táxons incluídos na família. O gênero Cathorops (Jordan \& Gilbert, 1883) inclui espécies do continente americano, caracterizadas pela ausência das placas de dentes associadas ao vômer e presença de um par de placas acessórias pequenas e ovaladas, providas de dentes molariformes. Muitas das espécies nominais incluídas em Cathorops apresentam status taxonômico indefinido devido às dificuldades encontradas no reconhecimento de suas identidades. Cathorops spixii (Agassiz, 1829) é o nome disponível mais antigo da costa oriental da América do Sul e tratado como sinônimo sênior das demais espécies nominais conhecidas (EIGENMANN \& EigenManN, 1890; Jordan \& EvERMAnN, 1898; Eigenmann, 1912; TAylor \& MenEzes, 1977). TAYlor \& Menezes (1977), no guia de identificação dos Ariidae da costa leste da América Central e norte da América do Sul, reconheceram Cathorops aguadulce (Meek, 1904) e
Cathorops melanopus (Günther, 1864) como válidas, enquanto as demais espécies pertencentes a Cathorops foram incluídas provisoriamente em um complexo denominado "Cathorops spixii".

Um dos objetivos do presente trabalho é reavaliar o status taxonômico de Arius arenatus Valenciennes, 1840, Arius fissus Valenciennes, 1840, Tachisurus agassizii Eigenmann \& Eigenmann, 1888 e Arius pleurops Boulenger, 1897 e fornecer uma diagnose adequada das espécies válidas de Cathorops. Outro objetivo é redefinir os caracteres morfométricos empregados em descrições e chaves para espécies da família Ariidae, a fim de uniformizar seu uso.

\section{MATERIAL E MÉTODOS}

As espécies foram diferenciadas e caracterizadas com base na análise de 54 caracteres morfométricos e 6 merísticos. As medidas e contagens foram tomadas, sempre que possível, no lado esquerdo dos exemplares, com ictiômetro com precisão de 1 milímetro e paquímetro com precisão de 0,01 milímetro. Na secção dimorfismo sexual e nas tabelas, os caracteres morfométricos são apresentados como percentagem do comprimento padrão e na secção diagnose como proporção do comprimento padrão e do diâmetro da órbita. O sexo dos exemplares examinados foi determinado através da observação das gônadas sob microscópio estereoscópico. Os caracteres morfológicos que mostraram diferenças entre machos e fêmeas são apresentados na secção dimorfismo sexual de cada espécie. Na sinonímia e na secção material examinado, a localidade citada foi corrigida e/ou traduzida quando necessário. 
Os caracteres morfométricos correntemente empregados em descrições e chaves da família Ariidae foram redefinidos para padronizar a forma dos caracteres a serem mesurados. Novos caracteres foram utilizados, a saber: distância entre o etmóide lateral e o supracleitro (DElSc); largura do escudo cefálico na região dos etmóides laterais (LEcEl); largura do escudo cefálico na região dos epoccipitais (LEcEp); largura do escudo cefálico na região dos frontais (LEcFr); largura do escudo cefálico na região do supracleitro $(\mathrm{LEcSc})$.

Acrônimos morfométricos: AAd, altura da nadadeira adiposa: maior distância vertical da base à margem superior (Fig. 1); AAn, altura da nadadeira anal: da base à extremidade do raio mais longo (Fig. 1); AC, altura do corpo: maior distância vertical entre a quilha do coracóide e o supra-occipital, em ângulo reto em relação ao eixo do corpo (Fig.1); AP, altura do pedúnculo caudal: menor distância vertical entre a margem dorsal e ventral do pedúnculo caudal (Fig. 1); APv, altura da nadadeira pélvica: da base à extremidade do raio mais longo (Fig. 1); CAP, comprimento do acúleo peitoral: da base, na altura da cavidade glenoidal, à extremidade, com o acúleo ereto (Fig. 2a); CAR, comprimento do acúleo dorsal: da base, na confluência entre a trava do acúleo e a placa nucal, à extremidade, com o acúleo ereto (Fig. 1); CBAd, comprimento da base da nadadeira adiposa: da margem anterior à margem posterior, basalmente (Fig. 1); CBAn, comprimento da base da nadadeira anal: da margem anterior do primeiro raio à margem posterior do último raio, basalmente (Fig. 1); CBM, comprimento do barbilhão maxilar: da inserção à extremidade (Fig. 2a); CBME, comprimento do barbilhão mental externo: da inserção à extremidade (Fig. 2a); CBMI, comprimento do barbilhão mental interno: da inserção à extremidade (Fig. 2a); $\mathrm{CBPv}$, comprimento da base da nadadeira pélvica: da margem anterior do primeiro raio à margem posterior do último raio, basalmente (Fig. 1); CC, comprimento da cabeça: da ponta do focinho à extremidade do opérculo, incluindo a porção membranosa (Fig. 1); CFc, comprimento do focinho: da ponta do focinho à margem anterior da órbita (Fig. 1); CLIC, comprimento do lobo inferior da nadadeira caudal: da base do primeiro raio procorrente inferior à extremidade do raio mais longo (Fig. 1); CLSC, comprimento do lobo superior da nadadeira caudal: da base do primeiro raio procorrente superior à extremidade do raio mais longo (Fig. 1); CP, comprimento padrão: da ponta do focinho à extremidade da placa hipural, detectada externamente através do dobramento lateral dos raios principais da nadadeira caudal (Fig. 1); CPA, comprimento da placa acessória de dentes: maior distância entre as margens anterior e posterior da placa (Fig. 2b); CPAd, comprimento do prolongamento da nadadeira adiposa: da margem posterior da nadadeira adiposa, basalmente, à extremidade da porção livre (Fig. 1); CPN, comprimento da placa nucal: maior distância entre as margens anterior e posterior (Fig. 3); CPO, comprimento do processo occipital: da margem superior do sulco medial à extremidade da porção mediada do processo occipital (Fig. 3); CT, comprimento total: da ponta do focinho à extremidade do lobo superior da nadadeira caudal (Fig. 1); DElSc, distância entre corno lateral do etmóide lateral e o ramo externo do supracleitro: da margem posterior do corno lateral do etmóide lateral à margem anterior do ramo externo do supracleitro (Fig. 3); DmO, diâmetro da órbita: maior distância horizontal entre as margens internas da órbita (Fig. 3); DNA, distância entre as narinas anteriores: menor distância entre as margens internas das narinas anteriores (Fig. 3); DNAO, distância entre a narina anterior e a órbita: menor distância entre as margens internas da narina anterior e da órbita (Fig. 3); DNP, distância entre as narinas posteriores: menor distância entre as margens internas das narinas posteriores (Fig. 3); DNPO, distância entre a narina posterior e a órbita: menor distância entre as margens internas da narina posterior e da órbita (Fig. 3); DO, distância interorbital: menor distância entre as margens superiores internas das órbitas (Fig. 3); DPA, distância entre as placas acessórias de dentes: maior distância entre as margens internas das placas da região do palato (Fig. 2b); FB, flecha bucal: comprimento da flecha geométrica compreendida entre o arco formado pela curvatura do bordo da mandíbula e a corda constituída pela largura da boca (Fig. 2a); FcAd, distância entre o focinho e a nadadeira adiposa: da ponta do focinho à margem anterior da nadadeira adiposa, basalmente (Fig. 1); FcAn, distância entre o focinho e a nadadeira anal: da ponta do focinho à margem anterior do primeiro raio da nadadeira anal, basalmente (Fig. 1); FcBM, distância entre o focinho e o barbilhão maxilar: da ponta do focinho à origem do barbilhão maxilar (Fig. 1); FcBME, distância entre o focinho e o barbilhão mental externo: da ponta do focinho à margem anterior do barbilhão mental externo, basalmente (Fig. 2a); FcBMI, distância entre o focinho e o barbilhão mental interno: da ponta do focinho à margem anterior do barbilhão mental interno, basalmente (Fig. 2a); FcDr, distância entre o focinho e a nadadeira dorsal: da ponta do focinho à margem anterior do acúleo dorsal, acima da trava do acúleo, com o acúleo ereto (Fig. 1); FcPt, distância entre o focinho e a nadadeira peitoral: da ponta do focinho à margem anterior do acúleo peitoral, na altura da cavidade glenoidal, com o acúleo ereto (Fig. 1); FcPv, distância entre o focinho e a nadadeira pélvica: da ponta do focinho à margem anterior do primeiro raio da nadadeira pélvica, basalmente (Fig. 1); FcSm, distância entre o focinho e a margem posterior do sulco medial: da ponta do focinho à margem posterior do sulco medial (Fig. 3); LB, largura da boca: maior distância entre as margens internas dos ângulos da boca (Fig. 2a); LC, largura do corpo: maior distância entre as margens externas da cintura escapular (Fig. 2a); LEcEl, largura do escudo cefálico na região dos etmóides laterais: maior distância entre as margens externas dos cornos laterais dos etmóides laterais (Fig. 3); LEcEp, largura do escudo cefálico na região dos epoccipitais: menor distância entre as margens laterais do processo posterior do epoccipital (Fig. 3); LEcFr, largura do escudo cefálico na região dos frontais: menor distância entre as margens externas dos frontais (Fig. 3); LEcSc, largura do escudo cefálico na região dos supracleitros: maior distância entre as margens externas dos supracleitros (Fig. 3); LLbI, largura do lábio inferior: maior distância entre as margens externas do lábio inferior (Fig. 2a); LLbS, largura do lábio superior: maior distância entre as margens externas do lábio superior (Fig. 2a); LPA, largura da placa acessória de dentes: maior 
distância entre as margens laterais da placa acessória de dentes (Fig. 2b); LPM, largura das placas do pré-maxilar: maior distância entre as margens laterais dos pré-maxilares (Fig. 2b); LPN, largura da placa nucal: maior distância entre as margens externas da placa nucal (Fig. 3); LPO, largura da região distal do processo occipital: menor largura da região posterior do processo occipital (Fig. 3); MaCPM, maior comprimento do pré-maxilar: maior distância entre as margens anterior e posterior do prémaxilar (Fig. 2b). As medidas CC, CFc, CP, CT, FcAd, FcAn, FcBM, FcBME, FcBMI, FcDr, FcPt, PcPv e FcSM foram tomadas através da projeção ortogonal dos pontos sobre o eixo do corpo e as demais restantes tomadas ponto a ponto.
Acrônimos merísticos. NRAn, número de raios na nadadeira anal; NRDr, número de raios na nadadeira dorsal; NRPt, número de raios da nadadeira peitoral; NRB1, número de rastros no primeiro arco branquial; NRB2, número de rastros no segundo arco branquial.

Acrônimos institucionais. AMNH - American Museum of Natural History, New York, E.U.A.; BMNH The Natural History Museum, London, Inglaterra; FMNH - Field Museum of Natural History, Chicago, E.U.A.; MCZ - Museum of Comparative Zoology, University of Harvard, Cambridge, E.U.A.; MNRJ - Museu Nacional, Rio de Janeiro, Brasil; MZUSP - Museu de Zoologia da Universidade de São Paulo, São Paulo, Brasil; RMNH National Natuurhistorisch Museum, Leiden, Holanda; USNM - National Museum of Natural History,

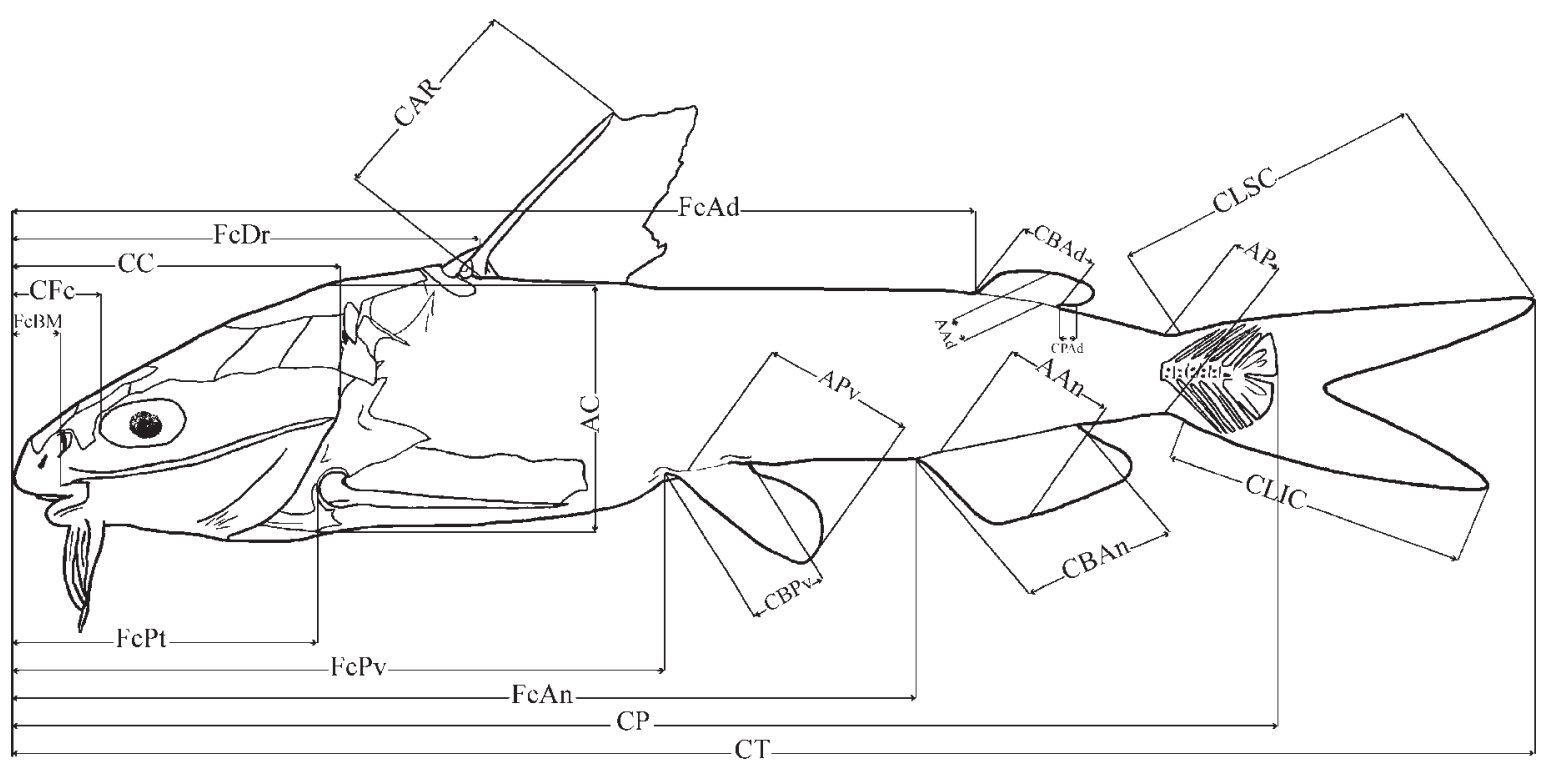

Fig. 1. Representação dos caracteres morfométricos. Corpo em vista lateral.


Fig. 2. Representação dos caracteres morfométricos. A, cabeça e porção anterior do corpo em vista ventral; B, pré-maxilar e placas acessórias de dentes. 
Smithsonian Institution, Washington D.C., E.U.A.; ZUES - Departamento de Zoologia da Universidade Federal do Espírito Santo, Brasil.

O material comparativo examinado. Cathorops dasycephalus (Günther, 1964). PANAMÁ, Balboa: baía do Panamá, 5, 09.II.1912, Meek \& Hildebrand cols. (FMNH 19143). COLÔMBIA, sul de Tumaco (ao largo de Cape Manglares), 7, 27.X.1970, L. Knapp col. (USNM 286481). Cathorops fuerthii (Steindachner, 1877). PANAMÁ, Balboa: baía do Panamá, 12, 09.II.1912, S. E. Meek \& S. F. Hildebrand cols. (USNM 79398). Cathorops hypophthalmus (Steindachner, 1877). PANAMÁ, Darien: rio Pirre (1/2 km acima de El Real), 2, 19.II.1985, J. L. Lundberg col. (USNM 293275). Cathorops mapale Betancur-R \& Acero, 2005. COLÔMBIA, Cienaga Grande de Santa Marta, 5, 17.IX.1970, Mahoma col. (USNM 286396); Cienaga la Virgen, 5, 06.VIII.1968 (USNM 286398). Cathorops melanopus (Günther, 1864). GUATEMALA, Izabal (rio Motagua, perto de Finca), 2, R. M. Bailey, D. E. Rosen \& R. P. Vari cols. (AMNH 35241). Cathorops multiradiatus (Günther, 1864). PANAMÁ, Balboa: baía do Panamá, 2, 05-06.V.1911, S. E. Meek \& S. F. Hildebrand cols. (USNM 79408). COLÔMBIA, sul de Tumaco (ao largo do Cabo Manglares), 3, 27.X.1970, L. Knapp col. (USNM 286400); Canchaco (Sandy Beach, enseada de Juan Chaco), 1, 18.IX.1969, L. Knapp col. (USNM 292703). Cathorops spixii (Agassiz, 1829). GUIANA FRANCESA, 0459'N, 51 ${ }^{\circ} 58^{\prime} \mathrm{W}, 2$, 03.VII.1975, B. B. Collette col. (USNM 286461). BRASIL, Pará: Vigia, 3, 07.VIII.1979, J. C. Oliveira col. (MZUSP 37214); baía de Marajó, 6, 25-29.V.1982, R. Barthem col. (MZUSP 49345); Coroinha (baía de Marajó), 2, 11.XII.1984, R. Barthem col. (MZUSP 49411); Maguari (Ponta Fina, baía de Marajó), 1, 16.V.1984, R. Barthem col. (MZUSP 49348); Maranhão: Pajé (estreito do Coqueiro, Ilha de São Luís), 2, 14.VII-08.IX.1982, Labohidro col. (MZUSP 37215); Paraíba: Lucena, 1, 04.VII.1995, Nepreamar col. (MZUSP 49350); 1 , 20.VII.1995, Nepreamar col. (MZUSP 49351); 1, 18.XI.1995,

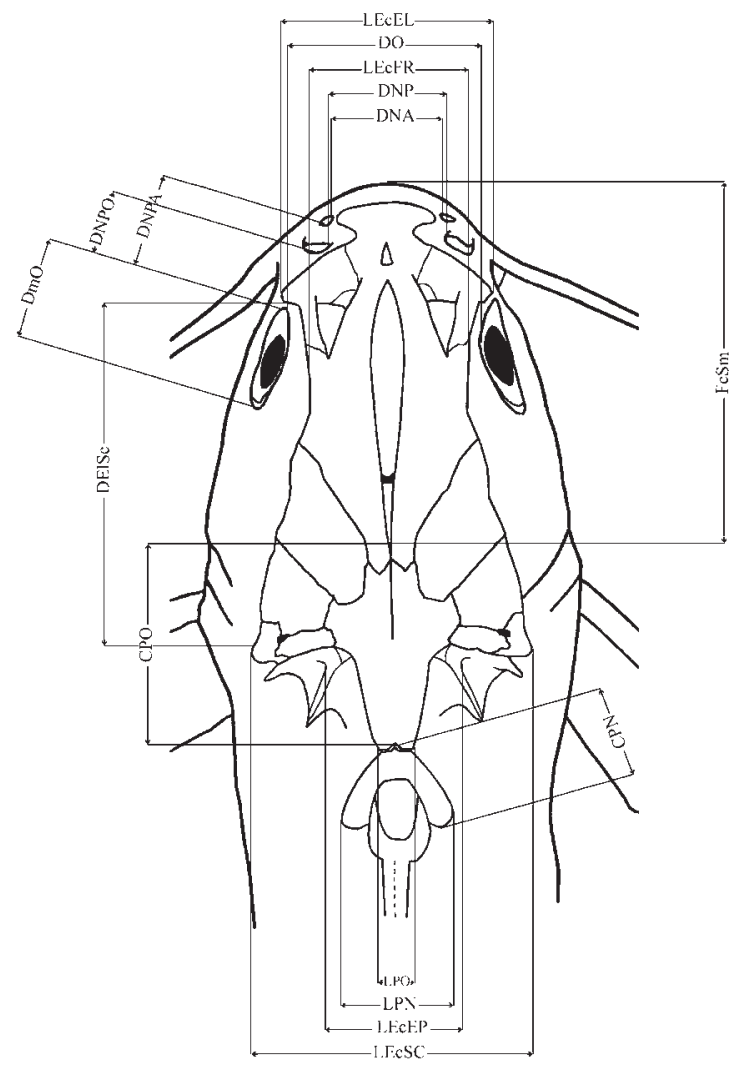

Fig. 3. Representação dos caracteres morfométricos. Cabeça e porção anterior do corpo em vista dorsal.
Nepreamar col. (MZUSP 49349); Sergipe: rio Sergipe, 4, IV.1981, A. V. Alcântara col. (MZUSP 37236); 16, IV.1981, A. V. Alcântara col. (MZUSP 49363); próximo a Pirambú (rio Japaratuba), 2, 21.XII.1978, A. V. Alcântara col. (MZUSP 49357); Bahia: Barra da Areia, 1, 1961, A. Miranda-Ribeiro col. (MNRJ 825); próximo de Maragogipe (boca do rio Paraguassú), 2, 13.X.1971, A. V. Alcântara col. (MZUSP 24374); Espírito Santo: baía de Camburí, 3, 02.VIII.1981, Zamprogno \& Helmaer cols. (ZUES 130023); boca do rio Doce, 2, 11.VIII.1969, Oc. W. Besnard, col. (MZUSP 23641); Rio de Janeiro: São João da Barra (rio Paraíba), 2, XII.1911, Garbe col. (MZUSP 2300); Atafona, 1, 27.VII.1963, IO-USP col. (MZUSP 22683); Pontal de Atafona, 31, 19.III-09.IV.1964, IO-USP col. (MZUSP 49353); Macaé (Portinha), 10, 06.VII.1972, N. Yamagut col. (MZUSP 24487); lagoa Marica, 1, 12.I.1964, IO-USP col. (MZUSP 22783); baía de Sepetiba, 2, 28.XI.1989, A. Begossi col. (MZUSP 48526); Saquarema (lagoa de Saquarema), 3, VII.1980, G. W. Nunan col. (MNRJ 11547); Ilha Grande, 300, V.1966, IO-USP col. (MZUSP 23127); Angra dos Reis, 1, (MZUSP 49352); São Paulo: Caraguatatuba (enseada de Caraguatatuba), 1, 31.V.1962, IO-USP col. (MZUSP 22571); Ubatuba (baía de Ubatuba), 8, 21.VI.1978, J. A. Coelho col. (MZUSP 24624); Guarujá (Ilha da Moela), 5, 18.V.1962, C. de Jesus col. (MZUSP 22572); Santos, 2, E. Rabelo col. (MZUSP 10090-91); 4, 1912, Von Ihering col. (MZUSP 2299); 38, 1986, A. Paiva col. (MZUSP 49362); baía de Santos, 3, 1918-79, CETESB col. (MZUSP 49360); Praia Grande, 1 (MZUSP 22216); Itanhaém, 1, 06.I.1961, E. Rabelo col. (MZUSP 22609); Cananéia, 1, 09.II.1962 (MZUSP 22491); 6, $23-$ 29.VIII.1971, G. R. Kloss col. (MZUSP 37240); 19, 1984-85, M. G. Ribeiro col. (MZUSP 49361); Valo Grande, 6, X.1984, CETESB col. (MZUSP 37239). Cathorops tuyra (Meek \& Hildebrand, 1923). PANAMÁ, rio Pirre (3-5 milhas acima de El Real, 08 $07^{\prime}$ N, $\left.77^{\circ} 42^{\prime} \mathrm{W}\right), 1$, 23.II-27.II.1967, N. W. Battelle col. (USNM 286397); 9, 24.II-27.II.1967, N. W. Battelle col. (USNM 286466); rio Uruseca ( 2 milhas acima de El Real, $\left.08^{\circ} 07^{\prime} \mathrm{N}, 77^{\circ} 45^{\prime} \mathrm{W}\right), 1,26 . I I .1967, \mathrm{~N}$. W. Battelle col. (USNM 286462); ( 5 milhas acima de El Real, $\left.08^{\circ} 07^{\prime} \mathrm{N}, 7^{\circ} 45^{\prime} \mathrm{W}\right), 5$, 26.II.1967, N. W. Battelle col. (USNM 292824). Cathorops sp. GUATEMALA, laguna Grande (2 milhas acima da boca do rio Sarstoon), 1 (USNM 114301). EL SALVADOR, La Libertad, 2 29.X.1975, M. Miller col. (USNM 286464). BELIZE, Belize city, 10, 02.VIII.1971, D. W. Greenfield \& J. E. Thomerson cols. (USNM 286399). HONDURAS, rio Cruta (Caratasca Lagoon), 5, 11.IV.1967, G. C. Miller col. (USNM 286763); 3, 11.IV.1967, G. C. Miller col. (USNM 286764); 5, 10.IV.1967, G. C. Miller col. (USNM 286765); 3, 10.IV.1967, G. C. Miller col. (USNM 286766). PANAMÁ, Aspinwall, 6, III-IV.1884 (USNM 38645); Mindi (Mindi Reef, zona do canal), 1, 07.IV.1911, S. E. Meek \& S. F. Hildebrand cols. (USNM 79415); Toro Point (zona do canal), 3, 12.IV.1911, S. E. Meek \& S. F. Hildebrand cols. (USNM 79345); 16, 12.IV.1911, S. E. Meek \& S. F. Hildebrand cols. (USNM 79355); Colon (mercado de peixe), 1, 11.I.1911, S. E. Meek \& S. F. Hildebrand cols. (USNM 79347); Colon (Fox Bay), 1, 05.I.1911, S. E. Meek \& S. F. Hildebrand cols. (USNM 79348); Cristobal (entrada do Canal do Panamá), 2, 20.IV.1911, S. E. Meek \& S. F. Hildebrand cols. (USNM 79350); Colon Reef, 26 (USNM 79363). COLÔMBIA, San Juan do sul (ao largo da boca do rio San Juan), 3, 20.X.1970, L. Knapp col. (USNM 286388); norte de Tumaco (ao largo da boca do rio San Juan), 2, 28.X.1970, L. Knapp col. (USNM 286389).

\section{RESULTADOS}

\section{Cathorops arenatus (Valenciennes, 1840)}

(Figs. 4 e 5; Tabs. I e II)

Arius arenatus VALENCIENNEs, 1840:106 (descrição original; espécime-tipo RMNH 3099; localidade-tipo Suriname; coletor Dieperink). Günther, 1864:172 (cópia de VAlenciennes, 1840). EIgENMANN, 1912:145 (nota no rodapé a respeito do status). BoesEman, 1972:298 (discussão a respeito do espécime-tipo).

Cathorops arenatus TAYLOR \& MENEZES, 1977:7 (comentário a respeito do status). MARCENIUK \& FERRARIs, 2003:449 (sinonímia e distribuição).

Arius fissus VALENCIENNES, 1840:107 (descrição original; espécimetipo RMNH 3036; localidade-tipo Suriname; coletor Dieperink). 
Tabela I. Dados morfométricos de Cathorops arenatus (Valenciennes, 1840). (A, espécime-tipo de Cathorops arenatus; B, espécime-tipo de Cathorops fissus (Valenciennes, 1840)). O comprimento total está expresso em milímetros e os caracteres morfométricos como percentagem do comprimento padrão. Acrônimos na seção Material e Métodos.

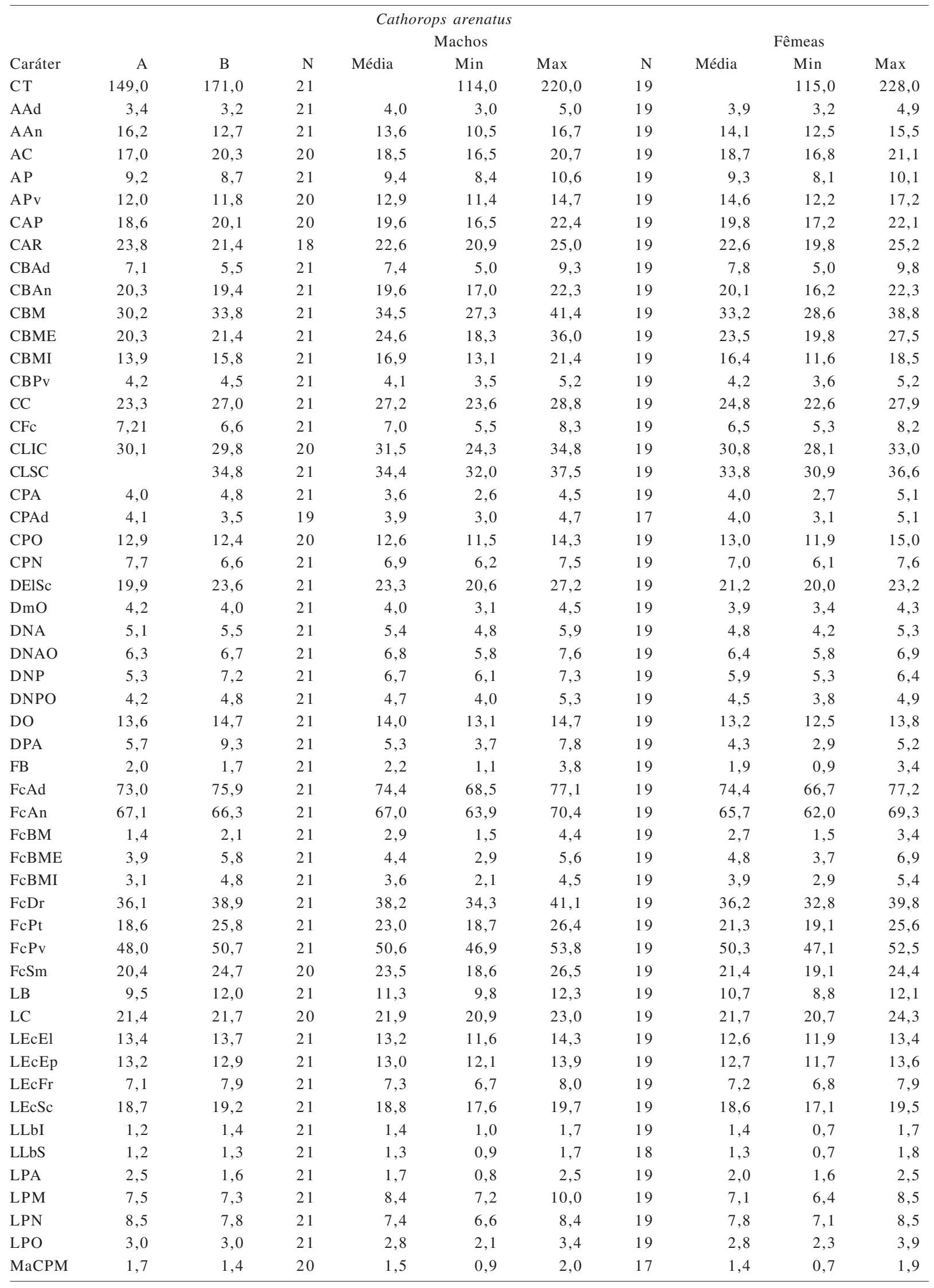


Günther, 1864:172 (cópia de Valenciennes e aspectos da reprodução). EigenMANN, 1912:145 (nota no rodapé a respeito do status). Puyo, 1949:41, 73 (descrição e diagnose). Boeseman, 1972:299 (discussão a respeito do espécime-tipo).

Tachisurus fissus Eigenmann \& Eigenmann, 1888:146 (somente nome). Eigenmann \& Eigenmann, 1890:49, 88 (somente citação na lista sinonímica).

Tachysurus fissus JoRDAN \& EvERMANN, 1898:131, 2782 (descrição). Cathorops fissus TAYLOR \& MENEZES, 1977:7 (comentário a respeito do status). MARCENiUK \& MENEZES, 2003:42 (distribuição).

Diagnose. Cathorops arenatus difere de Cathorops agassizii por possuir: olhos menores, cabendo 22,1-32,3 vs. 14,1-21,5 no comprimento padrão; barbilhão maxilar mais longos, cabendo 0,078-0,15 vs. 0,19-0,32 no diâmetro da órbita (Fig. 6); barbilhão mental externo mais longo, cabendo 0,11-0,22 vs. 0,26-0,52 no diâmetro da órbita; barbilhão mental interno mais longo, cabendo 0,15 0,35 vs. 0,40-0,88 no diâmetro da órbita; boca mais larga, cabendo 0,26-0,43 vs. 0,48-0,81 no diâmetro da órbita; corpo mais alto, cabendo 0,17-0,25 vs. 0,28-0,41 no diâmetro da órbita; corpo mais largo, cabendo 0,14-0,21 vs. 0,22-0,34 no diâmetro da órbita; crânio mais largo na região dos etmóides laterais, cabendo 0,23-0,34 vs. 0,350,58 no diâmetro da órbita; mais largo na região dos frontais, cabendo 0,44-0,68 vs. 0,73-1,2 no diâmetro da órbita; mais largo na região dos supracleitro, cabendo 0,17-0,24 vs. 0,27-0,40 no diâmetro da órbita; mais largo na região do epoccipitais, cabendo 0,23-0,36 vs. 0,41-0,62 no diâmetro da órbita; acúleo da nadadeira peitoral mais longo, cabendo 0,12-0,21 vs. 0,22-0,39 no diâmetro da órbita; processo occipital longo, cabendo 0,25-0,37 vs. 0,40-0,63 no diâmetro da órbita. Cathorops arenatus pode ser diferenciada de $C$. aguadulce, $C$. melanopus e $C$. fuerthii por apresentar maior número de rastros no primeiro arco branquial (17-23 vs. 13-16). Difere de $C$. dasycephalus pela ausência de granulação no processo

Tabela II. Dados merísticos de Cathorops arenatus (Valenciennes, 1840). (A, espécime-tipo de $C$. arenatus; B, espécime-tipo de $C$. fissus (Valenciennes, 1840)). Acrônimos na seção Material e Métodos.

\begin{tabular}{lrrrrrr}
\hline \multicolumn{7}{c}{ Cathorops arenatus } \\
Caráter & A & B & N & Média & Min & Max \\
NRAn & 24 & 22 & 37 & 22 & 21 & 24 \\
NRDr & 7 & 7 & 41 & 7 & 6 & 7 \\
NRPt & 9 & 10 & 41 & 10 & 9 & 10 \\
NRPv & 6 & 6 & 41 & 6 & 5 & 6 \\
NRB1 & 20 & 18 & 38 & 19 & 17 & 22 \\
NRB2 & 18 & 17 & 38 & 18 & 16 & 20 \\
\hline
\end{tabular}

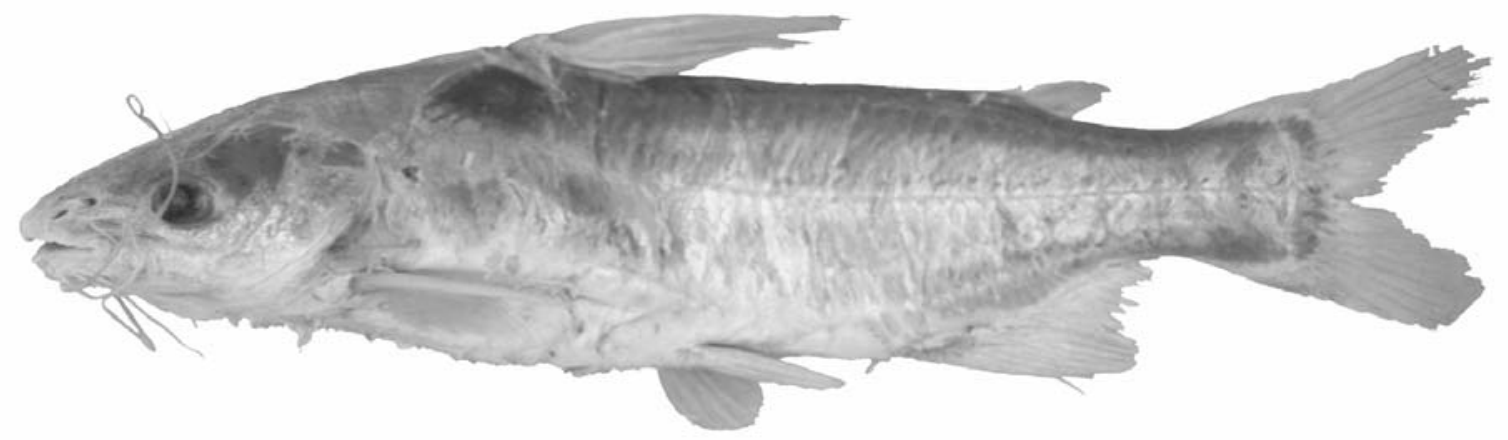

Fig. 4. Cathorops arenatus (Valenciennes, 1840), espécime-tipo, RMNH 3099, 149,0 mm de comprimento total. Corpo em vista lateral.

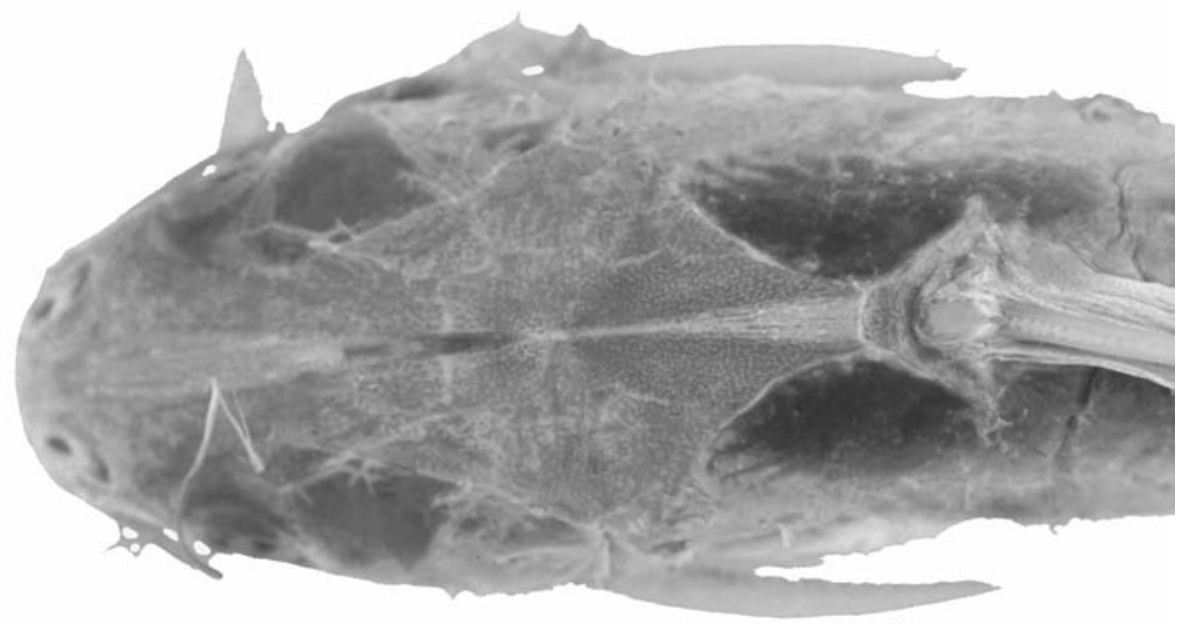

Fig. 5. Cathorops arenatus (Valenciennes, 1840), espécime-tipo, RMNH 3099, 149,0 mm de comprimento total. Cabeça em vista dorsal. 
anterior externo dos frontais ( $v s$. processo anterior externo dos frontais intensamente granulado), ausência das placas de dentes relacionadas ao vômer (vs. placas de dentes relacionadas ao vômer presentes) e placas acessórias com dentes molariformes ( $v s$. placas acessórias com dentes cônicos). Difere de C. hypophthalmus pelo menor número de rastros no primeiro e segundo arcos branquiais (13-23 no primeiro arco branquial e 13-22 no segundo vs. 37-40 no primeiro e segundo arcos branquiais) e olhos localizados acima do nível do ângulo da boca ( $v s$. olhos abaixo ou na mesma altura do ângulo da boca). Difere de $C$. multiradiatus por possuir menor número de raios na nadadeira anal (18-24 vs. 25-27) e a margem interna do acúleo da nadadeira peitoral com serrilhas curtas (vs. com serrilhas longas). Difere de $C$. spixii pelo sulco medial curto e estreito na porção mediana (vs. sulco medial longo, progressivamente mais amplo no sentido póstero-anterior). Distingue-se de $C$. tuyra pelo maior número de raios na nadadeira anal (21-24 vs. 19-20 raios) e placas acessórias com dentes molariformes grandes ( $v s$. placas acessórias com dentes molariformes muito grandes). Difere das demais espécies de Ariidae presentes nas Américas pela seguinte combinação de caracteres: placas de dentes relacionadas ao vômer ausentes; um único par de placas acessórias de dentes, pequenas e ovaladas; placas acessórias com dentes molariformes; nadadeira adiposa muito pequena, sendo o comprimento de sua base menor do que a metade do comprimento da base da nadadeira anal.

Descrição. Cabeça pouco deprimida, perfil ligeiramente convexo na região dos frontais e supraoccipital. Corpo mais largo do que alto na região da cintura peitoral. Escudo cefálico relativamente longo e largo. Rugosidade no escudo cefálico fina e irregularmente distribuída. Ponte óssea formada pelos frontais e etmóides laterais longa e delgada, bastante evidente sob a pele. Sulco medial mais estreito na porção mediana, as margens se tocando (ou quase) nesta região. Nas porções anterior e posterior as margens se afastam e são algo irregulares. Processo occipital longo e relativamente estreito na porção posterior, perfil bastante convexo. Placa pré-dorsal relativamente longa e estreita. Focinho arredondado em seção transversal e relativamente curto. Narinas anteriores e posteriores pouco distantes entre si. Olhos laterais pequenos, distância interorbital pouco pronunciada. Distância entre as narinas e a órbita relativamente pequena. Barbilhões longos, par maxilar ultrapassando a base do acúleo da nadadeira peitoral (ou alcançando a extremidade deste), par mental externo atingindo a base ou metade do comprimento do acúleo da nadadeira peitoral e par mental interno ultrapassando a membrana branquial. Boca ampla, maxila inferior pouco arqueada. Lábios relativamente espessos, o inferior mais espesso do que o superior. Placas de dentes associadas ao vômer ausentes. Placas acessórias de dentes ovais, mais próximas uma da outra na porção anterior. Placas acessórias com dentes molariformes grandes. Prémaxilares relativamente curtos e estreitos. Dentários com uma expansão posterior provida de dentes aciculares na porção anterior e dentes molariformes na porção posterior. Rastros branquiais aciculares, 17-22 no primeiro arco branquial, 6-8 no ramo superior e 11-14 no ramo inferior; segundo arco branquial com 16-20 rastros aculeiformes, 4-7 no ramo superior e 11-14 no ramo inferior. Nadadeiras peitorais com 9-10 raios moles. Acúleo da nadadeira peitoral espesso e longo, menor do que o acúleo da nadadeira dorsal, margem anterior com os dois terços basais granulados, terço distal serrilhado e a margem posterior com o quarto basal liso e três quartos distais com serrilhas curtas. Nadadeira dorsal com 6-7 raios moles. Acúleo da nadadeira dorsal espesso e longo, margem anterior com grânulos nos dois terços basais, terço distal serrilhado e a margem posterior quase toda serrilhada. Nadadeiras pélvicas com 6 raios moles, relativamente curtas na base e altas. Nadadeira anal com 21-24 raios moles, longa na base e alta. Nadadeira adiposa baixa e bastante curta na base, comprimento do prolongamento posterior bastante variável. Lobos superior e inferior da nadadeira caudal longos, o superior ligeiramente mais longo do que o inferior. Pedúnculo caudal relativamente alto. Linha lateral alcançando a base do lobo superior da nadadeira caudal.

Dimorfismo Sexual. Foram examinados 21 machos (114,0-220,0 mm de CT), 19 fêmeas (115,0-228,0 mm de CT) e 1 exemplar de sexo indeterminado. Diferenças entre os sexos são observadas quando comparados os valores médios dos caracteres mensurados.

A cabeça é relativamente mais longa e larga nos machos do que nas fêmeas. O maior comprimento da cabeça nos machos, fica evidenciado pelo comprimento da cabeça $(27,2$ vs. 24,8), comprimento do focinho $(7,01$ vs. 6,51), distância entre o focinho e a margem posterior do sulco medial $(23,5 v s .21,4)$ e distância entre corno lateral do etmóide lateral e o ramo externo do supracleitro (23,3 vs. 21,2). A maior largura da cabeça nos machos é caracterizada pela distância entre as narinas anteriores $(5,36$ vs. 4,75), distância entre as narinas posteriores $(6,74$ vs. 5,88), distância interorbital $(14,0$ vs. 13,2) e largura do escudo cefálico na região dos etmóides laterais (13,2 vs. 12,6). O maior comprimento da cabeça determina o aumento de toda porção anterior do corpo nos machos, como pode ser verificado através da distância entre a ponta do focinho e a origem da nadadeira peitoral $(23,0$ vs. 21,3), distância entre a ponta do focinho e a origem da nadadeira dorsal $(38,2$ vs. 36,2) e distância entre a ponta do focinho e a origem da nadadeira anal $(67,0 \mathrm{vs}$. 65,7).

As placas do pré-maxilar são mais largas nos machos $(8,42$ vs. 7,10$)$ e as placas acessórias de dentes mais longas $(3,98 v s .3,60)$ e largas $(1,99 v s .1,66)$ nas fêmeas do que nos machos (Fig. 7). Os machos apresentam as placas acessórias mais distantes uma da outra $(5,33$ vs. 4,34) (Fig. 7). Nos machos as placas acessórias possuem dentes menores e pouco numerosos, muitas vezes total ou parcialmente cobertos por tecido epitelial. Outra característica que difere com o sexo é o tamanho da expansão posterior do dentário, mais pronunciada posteriormente nas fêmeas e com dentes molariformes maiores e mais numerosos na porção posterior (Fig. 7).

Diferença significativa é observada em relação ao comprimento das nadadeiras pélvicas, mais altas (14,6 vs. 12,9) nas fêmeas do que nos machos. Por sua vez, os 
machos possuem barbilhões maxilares (34,5 vs. 33,2), barbilhões mentais externos $(24,6 v s$. 23,5), lobo superior (34,4 vs. 33.8) e lobo inferior da nadadeira caudal (31,5 vs. 30.8) mais longos do que as fêmeas.

Distribuição. Cathorops arenatus ocorre principalmente na faixa costeira não muito profunda, baías e desembocaduras de rios das regiões norte e nordeste da América do Sul, da boca do rio Orinoco na Venezuela para o sul, na Guiana, Suriname, Guiana Francesa e norte do Brasil, nos estados do Amapá e Pará (Fig. 8).

Comentários. Valenciennes (CUVIER \& VALENCIENNES, 1840) baseou a descrição de Arius arenatus (Figs. 4 e 5) e A. fissus (Figs. 9 e 10) em exemplares únicos, supostamente coletados em "Cayenne". As descrições originais foram elaboradas de forma bastante sucinta, abordando aspectos reconhecidos no presente estudo como pouco importantes para a diagnose das espécies. Segundo Valenciennes (Cuvier \& VAlEnCIENnEs, 1840), A. arenatus difere de $A$. fissus pelo menor comprimento da cabeça, maior tamanho dos dentes e maior tamanho das placas acessórias, que chegariam a se tocar na porção anterior. Aquele autor considerou ainda as espécies bastante semelhantes em relação as demais características examinadas. Eigenmann (1912) ao examinar exemplares identificados como A. fissus de "Cayenne" e do Suriname, depositados no Muséum National d'Histoire Naturelle e no National Natuurhistorisch Museum, considerou os exemplares muito similares a $A$. arenatus, reconhecida pelo autor como sinônimo júnior de C. spixii. EIGENMANN (1912) reconheceu que as espécies diferiam pelo comprimento da cabeça (3,4 e 3,6 vezes no comprimento total em A. fissus contra 3,9 vezes no comprimento total

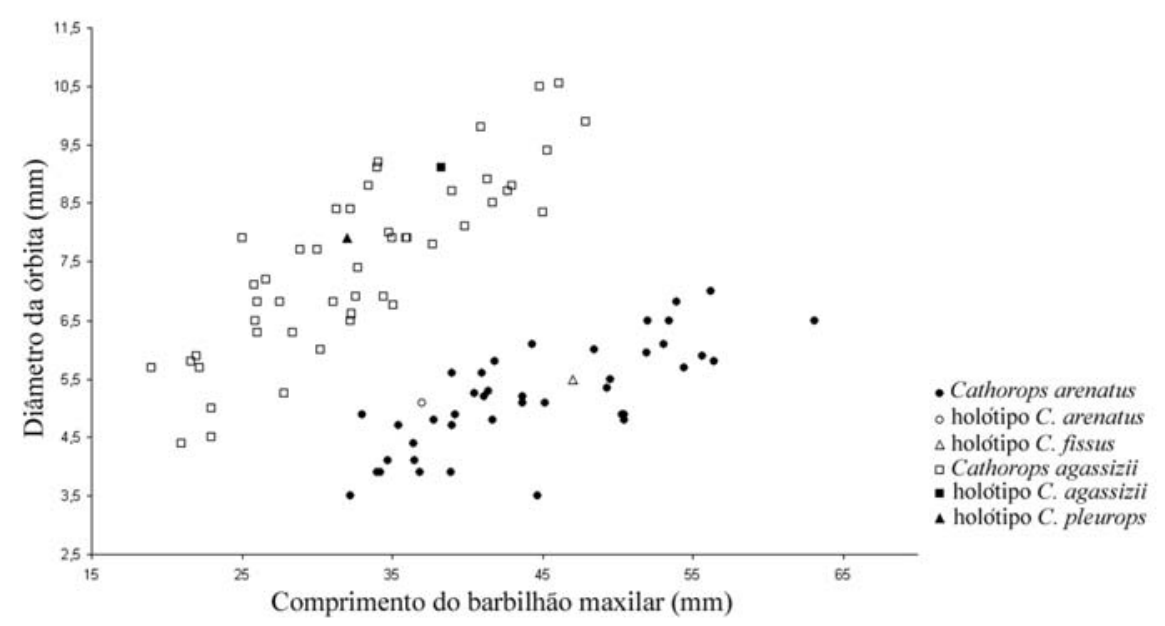

Fig. 6. Plotagem do comprimento do barbilhão maxilar (CBM) pelo diâmetro da órbita (DmO) de Cathorops arenatus (Valenciennes, 1840), C. fissus (Valenciennes, 1840), C. agassizii (Eigenmann \& Eigenmann, 1888) e C. pleurops (Boulenger, 1898).

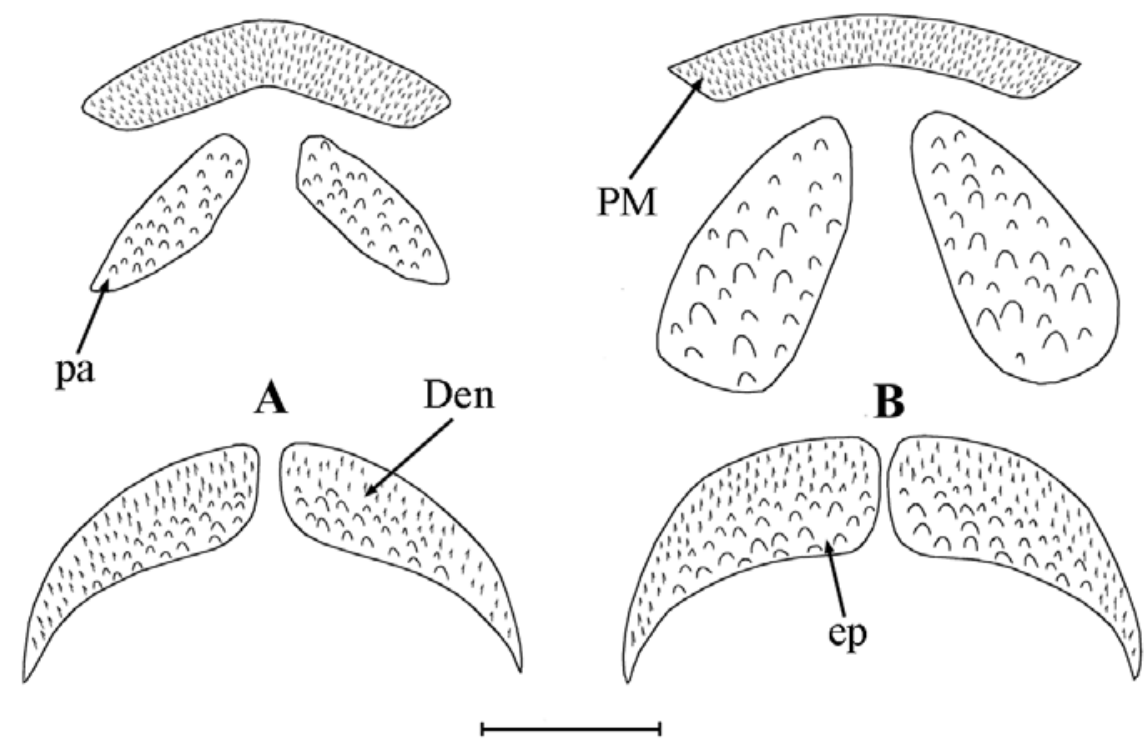

Fig. 7. Placas de dentes de Cathorops arenatus (Valenciennes, 1840). A, macho; B, fêmea. (Den, dentário; ep, expansão posterior; pa, placas acessórias; PM, pré-maxilar). Barra, $2 \mathrm{~mm}$. 
em $A$. arenatus) e nas placas acessórias menores em $A$. fissus. Segundo observações feitas no presente estudo, os caracteres empregados por Valenciennes (CUVIER \& VALENCIENNES, 1840) e EIGENMANN (1912) para distinguir as espécies apresentam diferenças entre machos e fêmeas. Desta forma, pode-se considerar que $A$. fissus teria sido descrita com base em um macho de $C$. spixii, enquanto $A$. arenatus teria sido estabelecida com base em uma fêmea de $C$. spixii. Contudo, o exame dos exemplarestipo e as descrições originais revelam uma característica única da espécie. O sulco medial do crânio, delimitado pelos frontais e o supraoccipital, estreito e curto com uma constrição na porção mediana (Figs. 5 e 10), permite diferenciar $C$. arenatus de $C$. spixii e $C$. agassizii. Cathorops arenatus pode ser ainda diferenciada de $C$. agassizii pelos barbilhões mais longos e os olhos menores.

BoESEMAN (1972) relatou que os espécimes-tipo de C. fissus (RMNH 3036) e C. arenatus (RMNH 3099) encontram-se depositados na coleção do Rijsksmuseum Van Natuurlijke Historie em Leiden e que Valenciennes (Cuvier \& VAlenciennes, 1840) errou ao citar "Cayenne" como localidade-tipo, pois Dieperink teria coletado os espécimes no Suriname. No presente estudo, $C$. arenatus é considerada espécie válida, tendo prioridade sobre $C$. fissus por ter sido publicada na página anterior do mesmo trabalho.

Material-tipo. Arius arenatus. Holótipo, SURINAME, Dieperink col. (RMNH 3099). Arius fissus. Holótipo, SURINAME, Dieperink col. (RMNH 3036).
Material complementar examinado. VENEZUELA, boca do rio Orinoco, 40, 27.II.1978, Baskin col. (USNM 233482). GUIANA, mercado de Georgetown, 1, IX-XII.1908, C. H. Eigenmann col. (USNM 66101). SURINAME, Nickerie: rio Corantijn ao largo de Clara Creek, 6, 05.IX.1980, R. P. Vari col. (USNM 225446); 1, 05.IX.1980, R. P. Vari col. (USNM 226106); $06^{\circ} 04^{\prime} \mathrm{N}-54^{\circ} 51^{\prime} \mathrm{W}, 17,13 . \mathrm{V} .1957$ (USNM 286395). GUIANA FRANCESA, $04^{\circ} 47^{\prime} \mathrm{N}-51^{\circ} 37^{\prime} \mathrm{W}, 16,05 . \mathrm{V} .1975$, B. B. Collette col. (USNM 286473); Pointe des Roches, 1, 30.V.1983, R. Beltran col. (MZUSP 37241). BRASIL, Amapá: $01^{\circ} 04^{\prime} \mathrm{N}-48^{\circ} 06^{\prime} \mathrm{W}, 11$, 13.V.1975, B. B. Collette col. (USNM 286750); $02^{\circ} 55^{\prime} \mathrm{N}$ $49^{\circ} 44^{\prime} \mathrm{W}, 1,09 . \mathrm{V} .1975$, B. B. Collette col. (USNM 286458); $03^{\circ} 16^{\prime} \mathrm{N}-50^{\circ} 03^{\prime} \mathrm{W}, 2$, 09.V.1975, B. B. Collette col. (USNM 286459); $03^{\circ} 33^{\prime}$ N $-50^{\circ} 17^{\prime}$ W, 5, 09.V.1975, B. B. Collette col. (USNM 286460); $04^{\circ} 59^{\prime} \mathrm{N}-51^{\circ} 58^{\prime} \mathrm{W}, 2$, 03.VII.1972, B. B. Collette col. (USNM 286461); $03^{\circ} 27^{\prime} \mathrm{N}-50^{\circ} 25^{\prime} \mathrm{W}, 2$, 09.V.1975, B. B. Collette col. (USNM 286463); $04^{\circ} 43^{\prime} \mathrm{N}-51^{\circ} 29^{\prime} \mathrm{W}, 5$, 06.V.1975, B. B. Collette col. (USNM 286465); $01^{\circ} 26^{\prime} \mathrm{N}-$ $48^{\circ} 14^{\prime} \mathrm{W}, 5$, 11.V.1975, B. B. Collette col. (USNM 286471); $00^{\circ} 24^{\prime}$ N-47 $47^{\circ}$ 'W, 10,13 .V.1975, B. B. Collette col. (USNM 286472); $03^{\circ} 16^{\prime} \mathrm{N}-50^{\circ} 12^{\prime} \mathrm{W}, 14,09 . \mathrm{V} .1975$, B. B. Collette col. (USNM 286390); $03^{\circ} 17^{\prime} \mathrm{N}-50^{\circ} 12^{\prime} \mathrm{W}, 7,09 . \mathrm{V} .1975$, B. B. Collette col. (USNM 286394); $02^{\circ} 16^{\prime} \mathrm{N}-48^{\circ} 47^{\prime} \mathrm{W}, 2$, 10.V.1975, B. B. Collette col. (USNM 286509); Pará: Jubim (baía de Marajó), 1, R. B. Barthem col. (MZUSP 48523); baía de Marajó, 5, 2529.V.1982, R. B. Barthem col. (MZUSP 49345); Vigia (mercado de peixe), 1, 08.IX.1987, J. C. Oliveira col. (MZUSP 49364).

Cathorops agassizii (Eigenmann \& Eigenmann, 1888) (Figs. 11 e 12; Tabs. III e IV)

Tachisurus agassizii EIGENMANn \& EIGENMANN, 1888:145 (descrição original; espécime-tipo MCZ 7670; localidade-tipo Rio Grande do Sul, Brasil; coletor Sr. Albuquerque). Eigenmann \& Eigenmann, 1890:86 (descrição).

Tachysurus agassizii MiRAndA-RIBEIRo, 1911:338 (descrição).
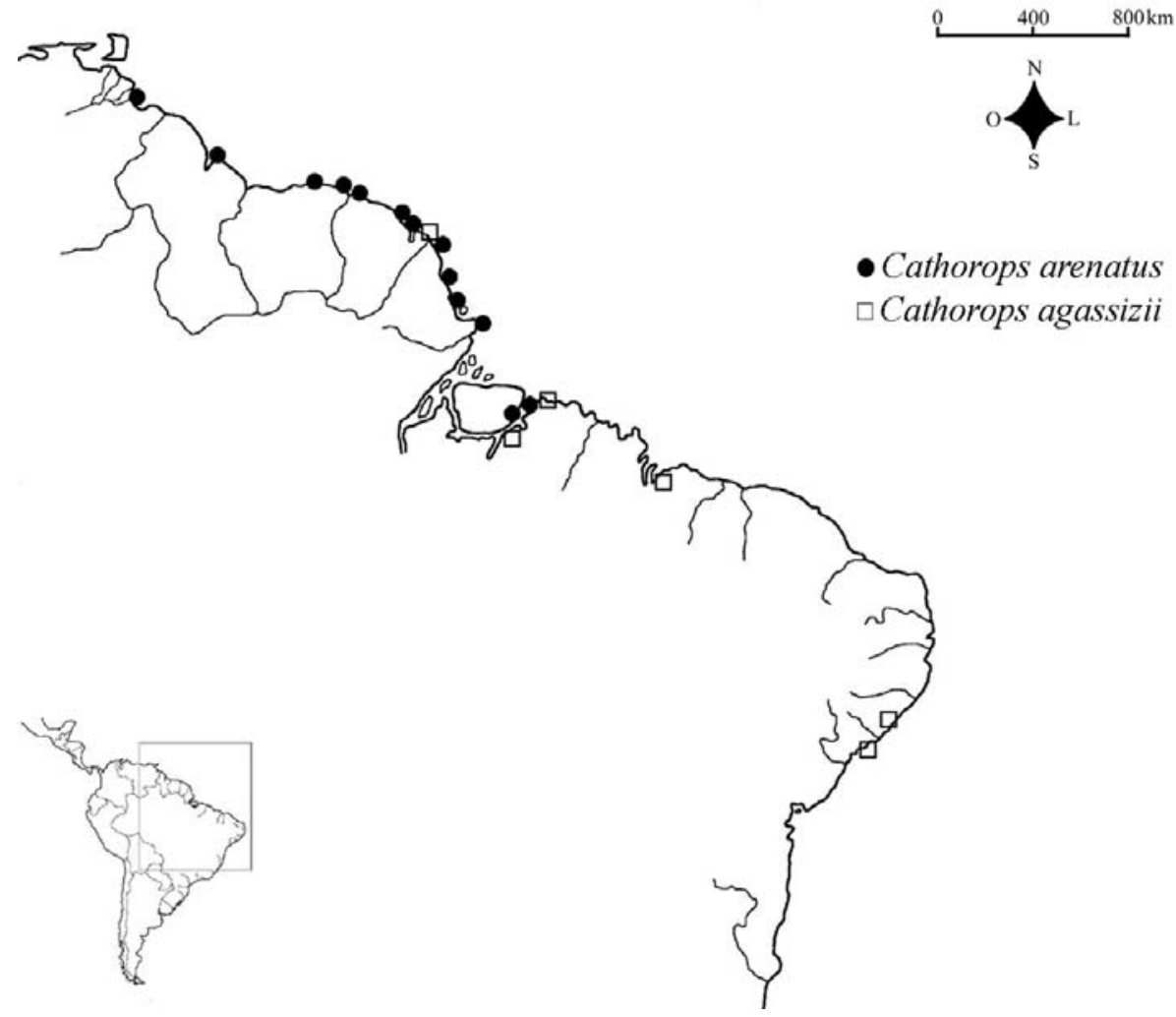

- Cathorops arenatus $\checkmark$ Cathorops agassizii

Fig. 8. Distribuição de Cathorops arenatus (Valenciennes, 1840) e C. agassizii (Eigenmann \& Eigenmann, 1888) no litoral da América do Sul, da boca do rio Orinoco na Venezuela, Guyana, Suriname, Guiana Francesa ao nordeste do Brasil. 


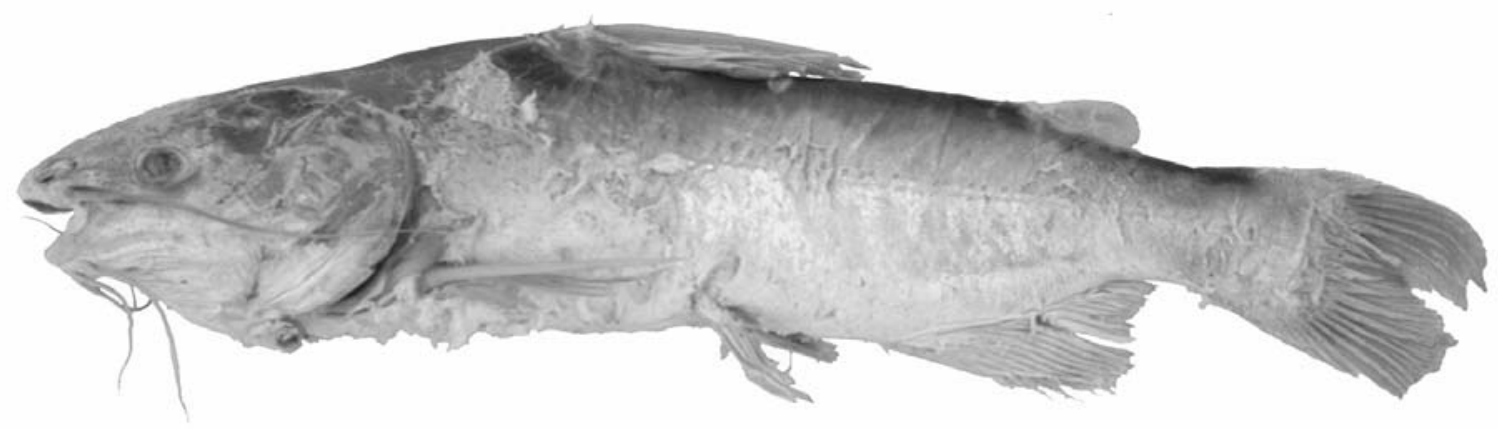

Fig. 9. Cathorops fissus (Valenciennes, 1840), espécime-tipo, RMNH 3036, 171,0 mm de comprimento total. Corpo em vista lateral.

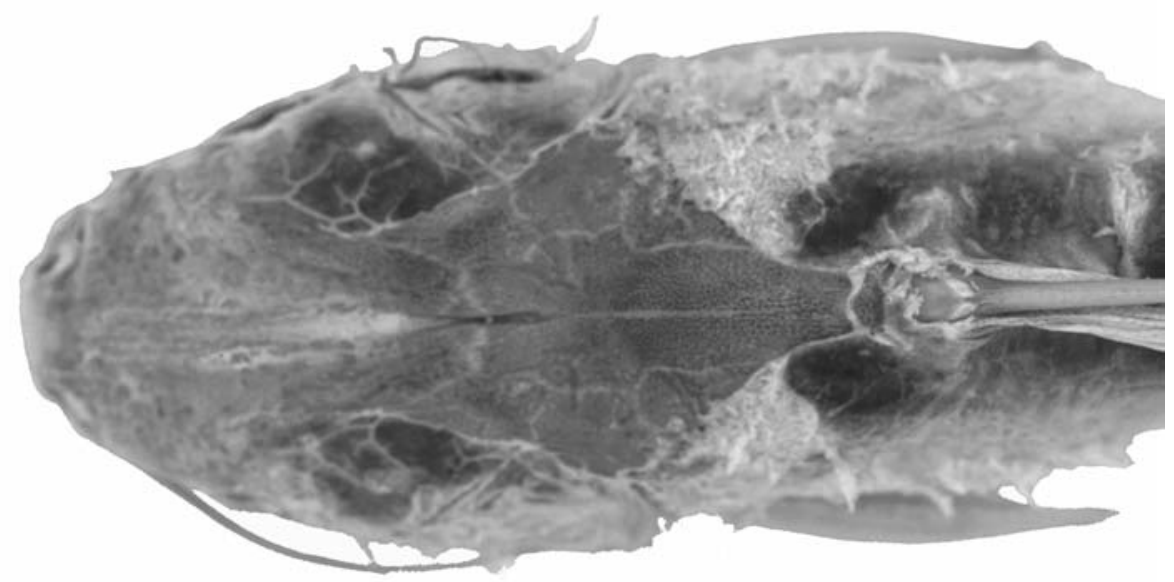

Fig. 10. Cathorops fissus (Valenciennes, 1840), espécime-tipo, RMNH 3036, 171,0 mm de comprimento total. Cabeça em vista dorsal.

Cathorops agassizii MARCENIUK \& Ferraris, 2003:449 (sinonímia e distribuição). Marceniuk \& Menezes, 2003:42 (distribuição).

Arius pleurops Boulenger, 1897:251 (descrição original; espécimetipo BMNH 1897.7.17.7; localidade-tipo Brasil, Marajó, coletor desconhecido).

Tachysurus pleurops MiRANDA-RIBEIRO, 1911:338 (descrição).

Cathorops pleurops TAYLOR \& MENEZES, 1977:7 (comentário a respeito do status). Marceniuk \& Menezes, 2003:42 (distribuição).

Diagnose. Cathorops agassizii difere de $C$. arenatus por possuir: olhos maiores, cabendo 14,1-21,5 vs. 22,1-32,3 no comprimento padrão; barbilhão maxilar mais curto, cabendo 0,19-0,32 vs. 0,078-0,15 no diâmetro da órbita (Fig. 6); barbilhão mental externo mais curto, cabendo 0,26-0,52 vs. 0,11-0,22 no diâmetro da órbita; barbilhão mental interno mais curto, cabendo 0,40-0,88 vs. 0,15-0,35 no diâmetro da órbita; boca mais estreita, cabendo 0,48-0,81 vs. 0,26-0,43 no diâmetro da órbita; corpo mais baixo, cabendo $0,28-0,41$ vs. $0,17-0,25$ no diâmetro da órbita; corpo mais estreito, cabendo 0,220,34 vs. 0,14-0,21 no diâmetro da órbita; crânio mais estreito na região dos etmóides laterais, cabendo 0,35-0,58 vs. 0,23-0,34 no diâmetro da órbita; mais estreito na região dos frontais, cabendo 0,73-1,2 vs. 0,44-0,68 no diâmetro da órbita; mais estreito na região dos supracleitros, cabendo 0,27-0,40 vs. 0,17-0,24 no diâmetro da órbita; mais estreito na região dos epoccipitais, cabendo 0,41-0,62 vs.
0,23-0,36 no diâmetro da órbita; acúleo da nadadeira peitoral mais curto, cabendo $0,22-0,39$ vs. 0,12-0,21 no diâmetro da órbita; processo occipital mais curto, cabendo 0,40-0,63 vs. 0,25-0,37 no diâmetro da órbita. Cathorops agassizii pode ser diferenciada de $C$. aguadulce, $C$. melanopus e $C$. fuerthii pelo maior número de rastros no primeiro arco branquial (17-23 vs. 13-16 rastros). Difere de $C$. dasycephalus pela ausência de granulação no processo anterior externo dos frontais ( $v s$. processo anterior externo dos frontais bastante granulado), ausência das placas de dentes relacionadas ao vômer ( $v s$. placas de dentes relacionadas ao vômer presentes) e placas acessórias de dentes com dentes molariformes ( $v s$. placas acessórias com dentes cônicos). Difere de $C$. multiradiatus por apresentar menor número de raios na nadadeira anal (18-24 vs. 25-27) e a margem interna do acúleo da nadadeira peitoral com serrilhas curtas ( $v s$. com serrilhas longas). Difere de C. hypophthalmus pelo menor número de rastros no primeiro e segundo arcos branquiais (13-23 no primeiro e 13-22 no segundo vs. 37-40 rastros no primeiro e segundo arcos) e olhos localizados acima do nível do ângulo da boca (vs. olhos localizados abaixo ou à mesma altura do ângulo da boca). Difere de C. tuyra e $C$. spixii por possuir barbilhões maxilares e mentais mais curtos, os maxilares quase nunca atingindo a base do acúleo da nadadeira peitoral (vs. sempre ultrapassando 
Tabela III. Dados morfométricos de Cathorops agassizii (Eigenmann \& Eigenmann, 1888). (A, espécime-tipo de Cathorops agassizii; B, espécime-tipo de Cathorops pleurops (Boulenger, 1897)). O comprimento total está expresso em milímetros e os caracteres morfométricos como percentagem do comprimento padrão. Acrônimos na seção Material e Métodos.

\begin{tabular}{|c|c|c|c|c|c|c|c|c|c|c|}
\hline \multicolumn{11}{|c|}{ Cathorops agassizii } \\
\hline \multirow[b]{2}{*}{ Caráter } & \multirow[b]{2}{*}{ A } & \multirow[b]{2}{*}{$\mathrm{B}$} & \multicolumn{4}{|c|}{ Machos } & \multicolumn{4}{|c|}{ Fêmeas } \\
\hline & & & $\mathrm{N}$ & Média & Min & $\operatorname{Max}$ & $\mathrm{N}$ & Média & Min & $\operatorname{Max}$ \\
\hline $\mathrm{CT}$ & 226,0 & 189,0 & 23 & & 102,0 & 267,0 & 24 & & 116,0 & 250,0 \\
\hline AAd & 2,6 & 3,1 & 19 & 3,6 & 2,9 & 4,6 & 23 & 4,0 & 3,2 & 5,0 \\
\hline AAn & 12,4 & 13,2 & 22 & 13,6 & 11,2 & 15,3 & 24 & 14,2 & 10,9 & 17,0 \\
\hline $\mathrm{AC}$ & 17,6 & 20,2 & 23 & 16,7 & 14,3 & 18,7 & 24 & 16,4 & 14,1 & 19,2 \\
\hline AP & 7,4 & 6,9 & 23 & 7,8 & 6,3 & 9,2 & 24 & 7,7 & 6,8 & 8,7 \\
\hline $\mathrm{APv}$ & 12,9 & 13,0 & 23 & 12,8 & 10,9 & 14,8 & 24 & 15,2 & 11,5 & 18,3 \\
\hline CAP & 17,6 & 18,0 & 19 & 18,1 & 16,6 & 19,7 & 12 & 18,1 & 15,7 & 20,5 \\
\hline CAR & 18,7 & 20,2 & 21 & 19,9 & 17,5 & 22,0 & 14 & 19,8 & 17,9 & 21,3 \\
\hline CBAd & 6,5 & 6,4 & 23 & 6,6 & 4,3 & 8,3 & 24 & 6,3 & 4,4 & 7,7 \\
\hline CBAn & 16,4 & 17,7 & 23 & 18,5 & 16,7 & 21,4 & 24 & 17,8 & 16,0 & 19,5 \\
\hline CBM & 20,5 & 20,3 & 23 & 23,6 & 19,4 & 27,6 & 24 & 25,1 & 18,8 & 31,3 \\
\hline CBME & 13,1 & 15,3 & 23 & 15,8 & 11,2 & 22,1 & 24 & 16,6 & 11,7 & 21,3 \\
\hline CBMI & & 8,9 & 23 & 10,5 & 8,3 & 15,6 & 24 & 11,0 & 6,8 & 14,8 \\
\hline $\mathrm{CBPv}$ & 3,7 & 3,5 & 22 & 3,7 & 2,7 & 4,9 & 24 & 3,5 & 2,7 & 4,4 \\
\hline $\mathrm{CC}$ & 27,2 & 29,5 & 23 & 26,5 & 22,8 & 29,3 & 24 & 26,2 & 23,5 & 31,6 \\
\hline $\mathrm{CFc}$ & 6,7 & 7,7 & 23 & 6,9 & 5,0 & 8,1 & 24 & 6,9 & 5,6 & 8,5 \\
\hline CLIC & 26,7 & 23,8 & 20 & 29,5 & 26,9 & 32,2 & 21 & 29,2 & 25,4 & 32,5 \\
\hline CLSC & 31,0 & 27,4 & 16 & 31,9 & 28,8 & 34,4 & 21 & 32,1 & 29,5 & 34,9 \\
\hline CPA & 3,2 & 3,4 & 23 & 3,1 & 2,4 & 4,8 & 24 & 3,2 & 2,3 & 4,7 \\
\hline CPAd & 2,7 & 2,8 & 21 & 3,5 & 2,8 & 5,5 & 23 & 3,4 & 2,4 & 4,6 \\
\hline $\mathrm{CPO}$ & 15,0 & 11,6 & 23 & 11,3 & 9,5 & 14,1 & 24 & 11,4 & 9,2 & 12,8 \\
\hline $\mathrm{CPN}$ & 6,8 & 6,8 & 23 & 7,0 & 6,0 & 8,2 & 24 & 7,0 & 6,2 & 7,6 \\
\hline DEISc & 24,6 & 24,6 & 23 & 23,5 & 20,3 & 25,6 & 24 & 22,5 & 19,5 & 25,7 \\
\hline $\mathrm{DmO}$ & 4,9 & 5,0 & 23 & 5,6 & 4,8 & 7,1 & 24 & 5,6 & 4,7 & 6,5 \\
\hline DNA & 5,1 & 5,2 & 23 & 4,7 & 3,5 & 5,7 & 24 & 4,4 & 3,3 & 4,9 \\
\hline DNAO & 6,6 & 7,2 & 23 & 6,4 & 5,7 & 7,5 & 24 & 6,2 & 5,2 & 6,7 \\
\hline DNP & 6,2 & 7,3 & 23 & 6,1 & 4,9 & 7,1 & 24 & 5,6 & 4,7 & 6,5 \\
\hline DNPO & 4,9 & 5,6 & 23 & 4,5 & 3,3 & 5,5 & 24 & 4,4 & 3,3 & 5,2 \\
\hline DO & 14,6 & 14,9 & 23 & 13,1 & 10,6 & 16,8 & 24 & 12,5 & 10,8 & 14,1 \\
\hline DPA & 7,1 & 7,5 & 23 & 5,2 & 3,5 & 6,4 & 24 & 4,7 & 3,2 & 6,4 \\
\hline FB & 2,8 & 2,3 & 23 & 2,6 & 1,5 & 3,5 & 24 & 2,2 & 1,3 & 2,9 \\
\hline FcAd & 75,1 & 77,8 & 23 & 76,6 & 73,0 & 79,3 & 24 & 76,3 & 68,9 & 81,0 \\
\hline FcAn & 69,8 & 70,6 & 23 & 66,9 & 62,4 & 69,4 & 24 & 66,9 & 61,9 & 70,0 \\
\hline $\mathrm{FcBM}$ & 1,9 & 2,3 & 23 & 2,4 & 1,3 & 3,4 & 24 & 2,4 & 1,7 & 3,9 \\
\hline FcBME & 2,6 & 2,1 & 23 & 3,4 & 2,3 & 4,4 & 24 & 3,8 & 2,1 & 5,2 \\
\hline FcBMI & 2,2 & 1,4 & 23 & 2,6 & 1,6 & 3,6 & 24 & 2,9 & 1,2 & 4,5 \\
\hline $\mathrm{FcDr}$ & 38,2 & 39,6 & 23 & 35,9 & 32,7 & 39,1 & 24 & 35,8 & 31,5 & 39,2 \\
\hline $\mathrm{FcPt}$ & 24,3 & 27,0 & 23 & 22,6 & 18,4 & 25,4 & 24 & 22,2 & 20,0 & 28,2 \\
\hline $\mathrm{FcPv}$ & 53,1 & 53,0 & 23 & 51,6 & 48,8 & 55,5 & 24 & 51,0 & 48,8 & 53,5 \\
\hline $\mathrm{FcSm}$ & 26,3 & 25,1 & 23 & 22,9 & 18,4 & 26,8 & 24 & 21,9 & 19,1 & 25,5 \\
\hline LB & 12,3 & 10,3 & 23 & 9,8 & 7,6 & 11,7 & 24 & 9,8 & 8,7 & 10,9 \\
\hline $\mathrm{LC}$ & 22,2 & 22,3 & 23 & 20,6 & 19,5 & 21,8 & 24 & 20,6 & 18,8 & 21,9 \\
\hline LEcEl & 14,0 & 14,1 & 23 & 12,6 & 11,6 & 14,0 & 24 & 11,9 & 10,8 & 13,3 \\
\hline LEcEp & 11,6 & 12,1 & 23 & 11,4 & 10,3 & 12,6 & 24 & 11,4 & 10,3 & 12,1 \\
\hline $\mathrm{LEcFr}$ & 7,0 & 6,8 & 23 & 6,3 & 5,5 & 7,2 & 24 & 6,0 & 5,0 & 7,2 \\
\hline LEcSc & 18,6 & 18,7 & 23 & 17,2 & 16,0 & 18,9 & 24 & 17,3 & 16,0 & 18,7 \\
\hline LLbI & 1,9 & 1,0 & 23 & 0,9 & 0,5 & 1,4 & 24 & 1,2 & 0,7 & 2,0 \\
\hline LLbS & 1,2 & 1,1 & 23 & 1,1 & 0,6 & 1,5 & 24 & 1,2 & 0,9 & 1,8 \\
\hline LPA & 1,0 & 1,0 & 22 & 1,3 & 0,9 & 2,1 & 24 & 1,5 & 0,6 & 2,4 \\
\hline LPM & 7,7 & 7,5 & 23 & 6,7 & 5,4 & 7,8 & 24 & 6,7 & 5,9 & 8,0 \\
\hline LPN & 7,3 & 7,5 & 23 & 6,8 & 5,9 & 7,6 & 24 & 6,8 & 6,2 & 7,4 \\
\hline LPO & 2,8 & 2,7 & 23 & 2,5 & 2,1 & 2,7 & 24 & 2,5 & 2,3 & 2,9 \\
\hline $\mathrm{MaCPM}$ & 1,2 & 1,3 & 21 & 1,3 & 1,0 & 1,8 & 24 & 1,8 & 1,0 & 2,0 \\
\hline
\end{tabular}


a base da nadadeira peitoral) e os mentais externos não atingindo a extremidade da membrana branquial ( $v s$. ultrapassando a extremidade da membrana branquial). Difere das demais espécies de Ariidae presentes nas Américas pela seguinte combinação de caracteres: placas de dentes relacionadas ao vômer ausentes; um único par de placas acessórias de dentes, pequenas e ovaladas; placas acessórias com dentes molariformes; nadadeira adiposa muito pequena, sendo o comprimento de sua base menor que a metade do comprimento da base da nadadeira anal.

Descrição. Cabeça deprimida, perfil ligeiramente convexo na região dos frontais e supra-occipital. Corpo mais largo do que alto na região da cintura peitoral. Escudo cefálico relativamente longo e estreito. Rugosidade fina no escudo cefálico. Ponte óssea formada pelos frontais e etmóides laterais muito longa e delgada, bastante evidente sob a pele. Sulco medial longo, progressivamente mais largo pósteroanteriormente e margens regulares em toda extensão. Processo occipital longo e largo na porção posterior, perfil convexo. Placa pré-dorsal longa e relativamente estreita. Focinho arredondado em seção transversal e relativamente curto. Narinas anteriores e posteriores relativamente próximas entre si. Olhos laterais grandes, distância interorbital pequena. Distância entre as narinas e a órbita pequena. Barbilhões curtos, par maxilar dificilmente alcançando a base do acúleo da nadadeira peitoral, par mental externo não ultrapassando a membrana branquial e par mental interno não atingindo a membrana branquial. Boca larga, maxila inferior pouco arqueada. Lábios relativamente finos, o superior mais espesso do que o inferior. Placas de dentes associadas ao vômer ausentes. Placas acessórias de dentes ovais, mais próximas uma da outra na porção anterior. Placas acessórias pequenas. Pré-maxilares estreitos e curtos. Dentário com ou sem uma expansão posterior conspícua, com dentes aciculares na porção anterior e dentes molariformes presentes ou não na porção posterior. Rastros branquiais aciculares, 19-23 no primeiro arco branquial, 6-8 no ramo superior e 12-16 no ramo inferior; segundo arco branquial com 16-20 rastros aculeiformes,



Fig. 11. Cathorops agassizii (Eigenmann \& Eigenmann, 1888), espécime-tipo, MCZ 7670, 226,0 mm de comprimento total. Corpo em vista lateral.

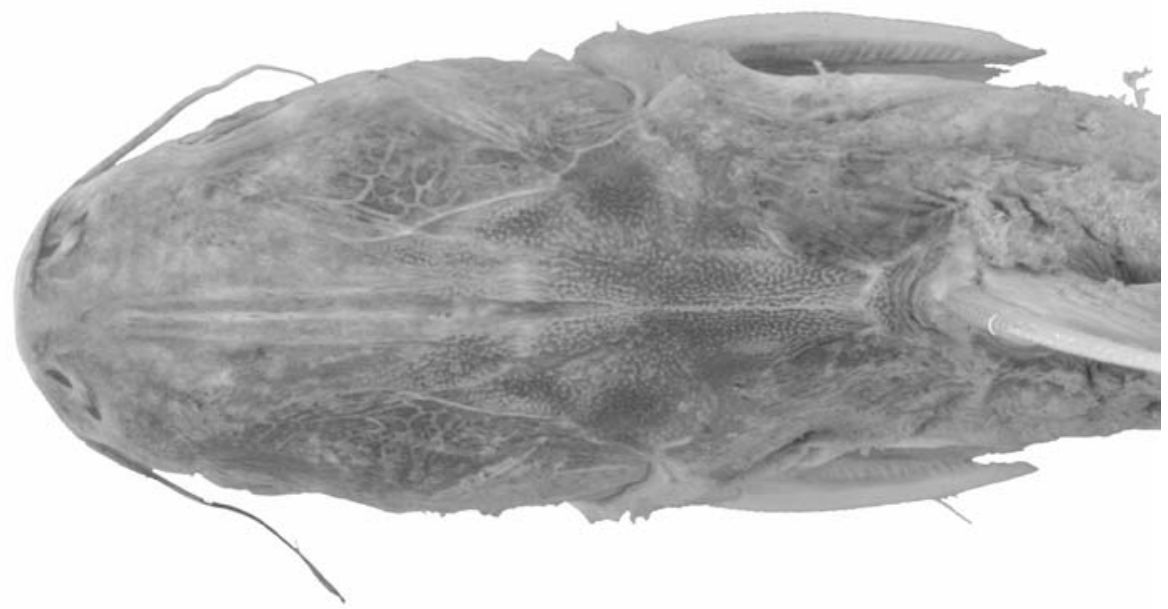

Fig. 12. Cathorops agassizii (Eigenmann \& Eigenmann, 1888), espécime-tipo, MCZ 7670, 226,0 mm de comprimento total. Cabeça em vista dorsal. 
4-7 no ramo superior e 11-13 no ramo inferior. Nadadeiras peitorais com 9-10 raios moles. Acúleo da nadadeira peitoral espesso e longo, menor do que o acúleo da nadadeira dorsal, margem anterior com poucos grânulos nos dois terços basais e terço distal serrilhado, margem posterior com o quarto basal liso e três quartos distais com serrilhas curtas. Nadadeira dorsal com 7 raios moles. Acúleo da nadadeira dorsal espesso e longo, margem anterior com poucos grânulos nos dois terços basais, terço distal serrilhado e a margem posterior quase toda serrilhada. Nadadeiras pélvicas com 6 raios moles, longas e estreitas na base. Nadadeira anal com 21-23 raios moles, longa (na base) e alta. Nadadeira adiposa curta na base e baixa, prolongamento posterior bastante variável. Lobos superior e inferior da nadadeira caudal longos, o superior ligeiramente mais longo do que o inferior. Pedúnculo caudal relativamente baixo. Linha lateral alcançando a base do lobo superior da nadadeira caudal.

Dimorfismo Sexual. Foram examinados 23 machos (102,0-267,0 mm de CT), 24 fêmeas (116,0-250,0 mm de CT) e 1 exemplar de sexo indeterminado. Diferenças entre os sexos são observadas quando comparados os valores médios dos caracteres mensurados.

Os machos possuem a cabeça relativamente mais longa e larga do que as fêmeas. O maior comprimento da cabeça nos machos é evidenciado pela distância entre a ponta do focinho e a margem posterior do sulco medial $(22,9$ vs. 21,9$)$ e distância entre corno lateral do etmóide lateral e o ramo externo do supracleitro $(23,5$ vs. 22,5). A maior largura pode ser detectada pela distância interorbital $(13,1$ vs. 12,5), distância entre as narinas posteriores $(6,06$ vs. 5,64) e largura do escudo cefálico na região dos etmóides laterais $(12,6$ vs. 11,9).

As placas acessórias de dentes são mais largas nas fêmeas $(1,47 v s .1,33)$ e mais distantes uma da outra nos machos $(5,16$ vs. 4,74) (Fig. 13). As fêmeas apresentam placas acessórias com forma ovalada, enquanto nos machos as placas acessórias são mais longas e estreitas
(Fig. 13) e freqüentemente cobertas por uma densa camada de tecido epitelial. Os dentes molariformes das placas acessórias são maiores e mais numerosos nas fêmeas do que nos machos. Somente nas fêmeas a porção posterior do dentário apresenta uma projeção posterior com poucos dentes molariformes. Nos machos, o dentário na maioria das vezes não apresenta dentes molariformes na porção posterior, mas quando presentes são bastante pequenos (Fig. 13).

O lábio inferior é mais espesso nas fêmeas $(1,15 \mathrm{vs}$. $0,88)$, que possuem ainda o barbilhão maxilar $(25,1 \mathrm{vs}$. $23,6)$ e o barbilhão mental externo $(16,6$ vs. 15,8$)$ mais longos do que os machos. As nadadeiras anal (14,2 vs. $13,6)$ e pélvicas $(15,2$ vs. 12,8) são mais altas nas fêmeas do que nos machos.

Distribuição. Cathorops agassizii é comum em estuários, lagoas e rios costeiros da região nordeste da América do Sul, da Guiana Francesa, para o norte e nordeste do Brasil nos estados do Pará, Maranhão, Alagoas e Sergipe (Fig. 8).

Comentários. Tachisurus agassizii (Figs. 11 e 12) foi descrita por EIGENMANN \& EIGENMANN (1888), com base em exemplar único de 235,0 mm de CT, coletado pelo $\mathrm{Sr}$. Albuquerque supostamente no estado do Rio Grande do Sul, Brasil. A espécie foi diferenciada com base nos dentes

Tabela VI. Dados merísticos de Cathorops agassizii (Eigenmann \& Eigenmann, 1888). (A, espécime-tipo de Cathorops agassizii; B, espécime-tipo de Cathorops pleurops (Boulenger, 1897)). Acrônimos na seção Material e Métodos.

\begin{tabular}{lrrcccc}
\hline & \multicolumn{5}{c}{ Cathorops agassizii } \\
Caráter & A & B & N & Média & Min & Max \\
NRAn & 20 & 22 & 49 & 22 & 21 & 23 \\
NRDr & 7 & 7 & 49 & 7 & 7 & 7 \\
NRPt & 10 & 11 & 49 & 10 & 9 & 10 \\
NRPv & 6 & 6 & 48 & 6 & 6 & 6 \\
NRB1 & 21 & 20 & 48 & 21 & 19 & 23 \\
NRB2 & 17 & 20 & 47 & 18 & 16 & 20 \\
\hline
\end{tabular}
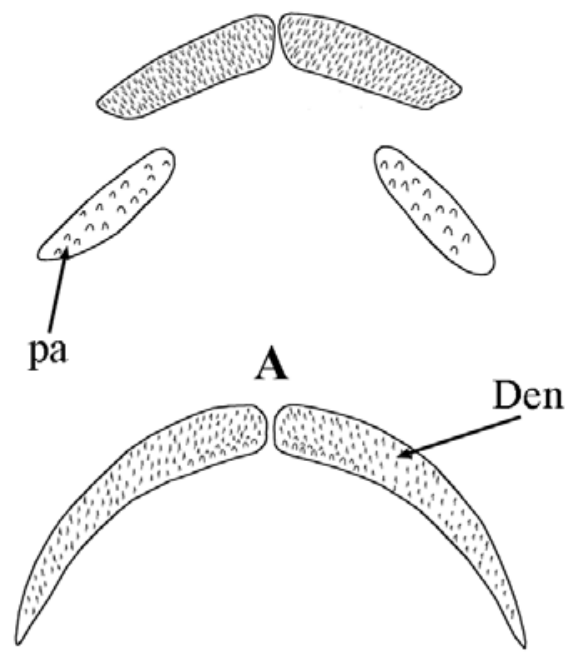

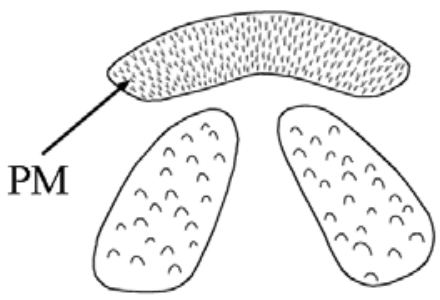

B

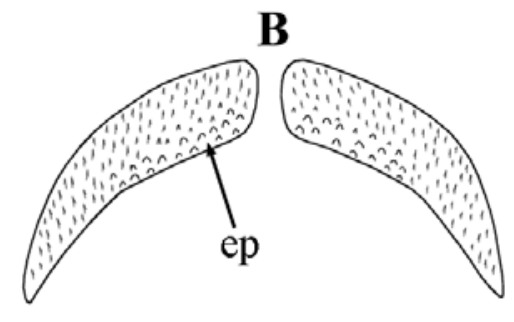

Fig. 13. Placas de dentes de Cathorops agassizii (Eigenmann \& Eigenmann, 1888). A, macho; B, fêmea. (Den, dentário; ep, expansão posterior; pa, placas acessórias; PM, pré-maxilar). Barra, $2 \mathrm{~mm}$. 
menores nas placas acessórias, na ausência de dentes molariformes na porção posterior do dentário e nas placas acessórias pequenas e distantes uma da outra em relação a C. spixii. Fica demonstrado na presente análise que o menor número ou ausência de dentes molariformes na porção posterior do dentário, o menor tamanho das placas acessórias e a maior distância entre elas são diferenças relacionadas ao sexo, características dos machos de C. agassizii. Diferenças relacionadas ao sexo também foram empregadas por outros autores na determinação de espécies de Cathorops (Cuvier \& Valenciennes, 1840, Günther, 1864 e Meek \& HILDEBRAND, 1923). O erro poderia induzir à conclusão de que T. agassizii seria sinônimo júnior de $C$. spixii, por ter sido descrito com base em um caráter dimorfico, porém o exame do exemplar-tipo e a descrição de EIGENMANN \& Eigenmann (1888) permitem reconhecer outras características que não diferem com o sexo e permitem distinguir a espécie das demais designadas ao gênero Cathorops. A descrição original detalha aspectos relacionados ao tamanho do olho e comprimento dos barbilhões, importantes para diagnose da espécie: "eye $1 \frac{1}{2}$ in snout, $51 / 3$ in head, about 3 in interocular 2 in interorbital space; maxillary barbels about reaching gill opening; mental extending about half way to gill opening, the post mentals not much longer" (EIGENMAnN \& EIGENMANN, 1888:145).

BOULENGER (1897) descreveu Arius pleurops (Figs. 14 e 15), com base em um macho de $170 \mathrm{~mm}$ de CT. O espécime analisado fazia parte da coleção de peixes formada pelo Dr. Emílio A. Goeldi, com material proveniente da Ilha de Marajó, Pará. A descrição original é breve, mas revela características peculiares da espécie, que tornam possível seu reconhecimento: "Anal 20; eye perfectly lateral, just behind and on a level with the angle of mouth, its diameter 5 times in length of head, $11 / 2$ in length of snout, $21 / 2$ in interorbital width; barbells short, not reaching gill-cleft; palatine teeth villiform, in two widely separated transverse patches which are narrower than the premaxillary band" (BOULENGER, 1897:296). O autor errou ao descrever os dentes das placas acessórias como viliformes, sendo estes na verdade molariformes. A confusão provavelmente tenha ocorrido devido aos machos da espécie possuírem dentes molariformes pequenos e menos numerosos do que as fêmeas e também pelo fato de que os machos apresentam (durante o período de desova) as placas acessórias cobertas por uma densa camada de tecido epitelial, o que dificulta a

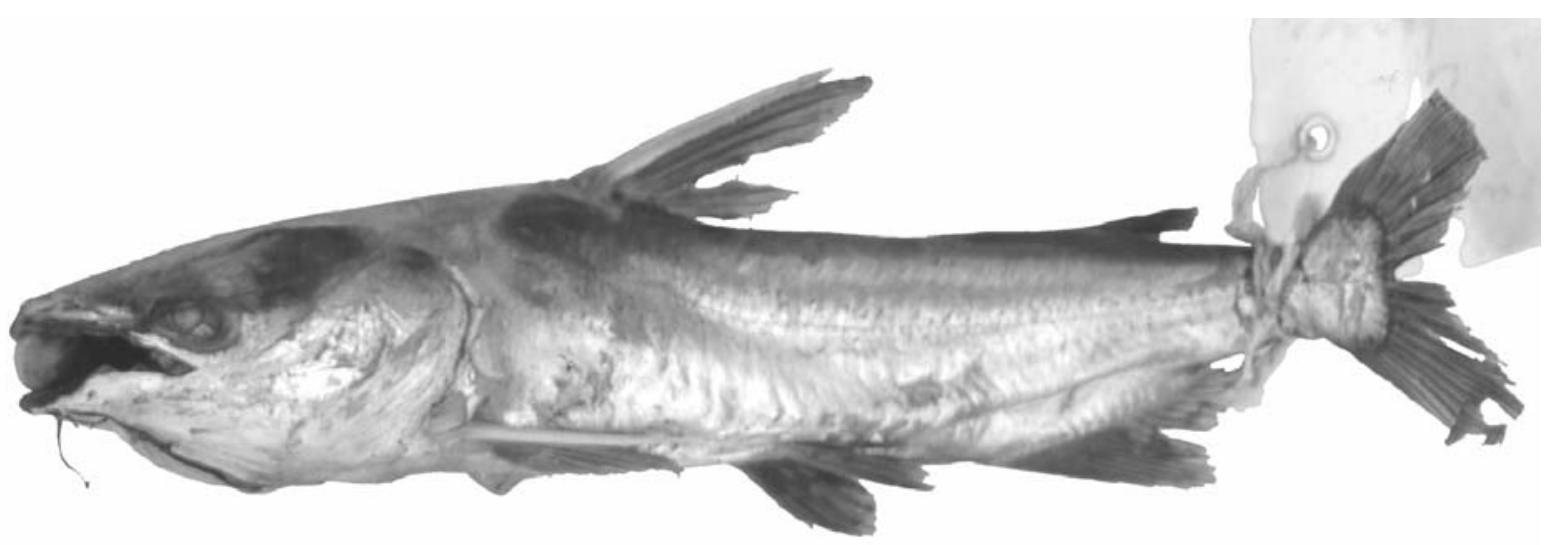

Fig. 14. Cathorops pleurops (Boulenger, 1897), espécime-tipo, BMNH 1897.7.17.7, 189,0 mm de comprimento total. Corpo em vista lateral.

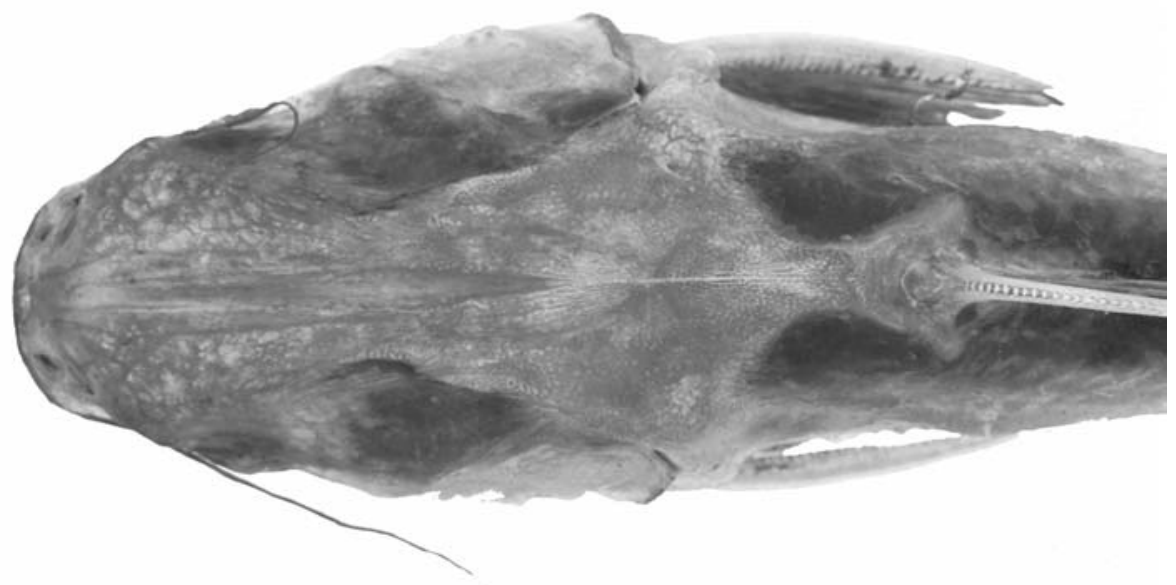

Fig. 15. Cathorops pleurops (Boulenger, 1897), espécime-tipo, BMNH 1897.7.17.7, 189,0 mm de comprimento total. Cabeça em vista dorsal. 
observação dos dentes. O exemplar descrito por BOULENGER encontrava-se em período de incubação, carregando na cavidade bucal 18 ovos de aproximadamente $8 \mathrm{~mm}$ de diâmetro e alguns embriões em adiantado estado de desenvolvimento (Fig. 14).

Em conclusão, $C$. agassizii é considerada espécie válida e $C$. pleurops seu sinônimo júnior. A localidade original citada por Eigenmann \& EIgENMAnN (1888) aparentemente foi mencionada de forma incorreta. A hipótese de erro na citação original é sustentada pela inexistência de qualquer registro de exemplares do gênero Cathorops no estado do Rio Grande do Sul, Brasil.

Material-tipo. Arius pleurops. Holótipo, BRASIL, Pará: Marajó, E. A. Goeldi col. (BMNH 1897.7.17.7). Tachisurus agassizii. Holótipo, BRASIL, Rio Grande do Sul: (localidade provavelmente incorreta), Sr. Albuquerque col. (MCZ 7670).

Material complementar examinado. GUIANA FRANCESA Barriêra, 3, 27.X.1981, R. Beltran col. (MZUSP 49412); Pointe des Roches, 1, 30.V.1983, R. Beltran col. (MZUSP s/n). BRASIL Pará: Vigia (mercado de peixe), 2, 08.IX.1987, J. C. Oliveira col (MZUSP 49347); Vigia, 1, 07.VIII.1978, J. C. Oliveira col (MZUSP 25169); Cajueiro (Ilha de Mosqueiro, baía de Marajó), 4, 15.XII.1984, R. Barthem col. (MZUSP 49346); Maranhão: Ilha de São Luís (estreito do Coqueiro), 1, 05.III.1983, Labohidro col. (MZUSP 37228); Ilha de São Luís (rio Curica), 1, 17.V.1982, Labohidro col. (MZUSP 49344); Alagoas: Maceió, 4, 1985, CETESB col. (MZUSP 37230); Maceió (lagoa de Mundaú), 8 , 1985, CETESB col. (MZUSP 37231); 17, III.1985, CETESB col. (MZUSP 37232); 5, X.1984, CETESB col. (MZUSP 37234); 2, 17.V.1973, N. A. Menezes col. (MZUSP 37235); 6, 09.XI.1988, R. Teixeira col. (MZUSP 49341); 1, III.1985, CETESB col. (MZUSP 49342); 2, 1985, CETESB col. (MZUSP 49343); 11, CETESB col. (MZUSP 51709); Sergipe: próximo a Pirambú (rio Japaratuba), 4, 07.VIII.1978, A. V. Alcântara col. (MZUSP 49355); 4, 06.VIII.1978, A. V. Alcântara col. (MZUSP 49356); 2, 21.XII.1978, A. V. Alcântara col. (MZUSP s/n); rio Sergipe, 3, X.1981, A. V. Alcântara col. (MZUSP 37237); 4, IV.1981, A. V. Alcântara col. (MZUSP 49358); 6, X.1981, A. V. Alcântara col (MZUSP 49359); próximo a Aracaju (boca do rio Pomongá), 1, 17.XII.1978, A. V. Alcântara col. (MZUSP 49354).

Considerações Taxonômicas. O gênero Cathorops inclui espécies do continente americano encontradas preferencialmente em regiões estuarinas e rios costeiros. As espécies do gênero formam um grupo monofilético facilmente reconhecido pela ausência das placas de dentes relacionadas ao vômer, um único par de placas acessórias pequenas e ovaladas providas de dentes molariformes e a nadadeira adiposa bastante curta. A taxonomia e sistemática das espécies de Cathorops é bastante confusa devido a grande semelhança da morfologia e a pouca consistência dos caracteres tradicionalmente empregados no reconhecimento das espécies.

As espécies nominais da costa leste da América do Sul correntemente incluídas em Cathorops, foram muitas vezes indevidamente reconhecidas como sinônimos de C. spixii (EIGENMANN \& EIGENMANN, 1890; JoRDAN \& Evermann, 1898; Eigenmann, 1912; TAylor \& MEnEzes, 1977). O nome C. spixii foi consagrado pela sua utilização em trabalhos sobre a sistemática e biologia dos Ariidae da costa oriental americana (TAYLOR \& MENEZES, 1977; Etchevers, 1978; Diaz \& Bashirullah, 1984; Mello \& TeiXeira, 1992; Acero, 2003). A ausência de uma boa definição de $C$. spixii levou a grande imprecisão dos limites da espécie e obscureceu a identidade de espécies distintas. TAYLOR \& MENEZES (1977) empregaram C. spixii para fazer referência a todas espécies do Atlântico incluídas em Cathorops, exceção a $C$. melanopus e $C$. aguadulce restritas a água doce. A correta determinação das espécies de Cathorops é importante devido sua grande abundância e importância ecológica em ambientes costeiros e estuarinos onde são encontradas (Mishima \& TANJI, 1981; LARA-DomingueZ et al. 1982; BARLETTA et al. 2003).

As espécies nominais Arius variolosus Valenciennes, 1840, Arius puncticulatus Valenciennes, 1840, Arius nuchalis Günther, 1864 e Arius laticeps Günther 1864, reconhecidas como espécies inquirendae por MARCENIUK \& FERRARIS (2003) são consideradas distintas de $C$. arenatus e $C$. agassizii com base nas descrições originais. $C$. arenatus difere destas espécies pelo sulco medial do crânio mais estreito na porção mediana e $C$. agassizii pelos barbilhões mais curtos e olhos maiores. C. arenatus e $C$. agassizii são diferenciadas de $C$. spixii com base em MARCENIUK (2005). A definição dos limites e redescrição de $C$. spixii serão tratados em publicação futura.

Agradecimentos. O trabalho é fundamentado nos resultados de tese de mestrado elaborada no Museu de Zoologia da USP. Desta forma, sou grato ao Prof. Dr. Naércio Aquino Menezes pela oportunidade de orientação e utilização da coleção Ictiológica do Museu de Zoologia da USP. Sou grato pelos comentários e sugestões (que muito contribuíram para redação final do trabalho) ao Dr. Naércio Aquino Menezes (MZUSP) e ao Dr. José Lima Figueiredo (MZUSP). Sou extremamente grato pelo apoio e atenção dispensada através do empréstimo de material aos seguintes profissionais e suas respectivas instituições: M. J. P. van Oijen (RMNH); Anne-Marie Woolger e Patrick D. Campbell (BMNH); Karsten E. Hartel (MCZ); Susan Jawett, Sandra Raredon e Lisa Palmer (USNM); Barbara Brown (AMNH); Osvaldo T. Oyakawa (MZUSP); Barry Chernoff e Mary Anne Rogers (FMNH); Décio F. de Morais Jr. e Gustavo W. Nunan (MNRJ). Agradeço a CAPES pelo apoio financeiro recebido através da concessão da bolsa de mestrado e a FAPESP pelas bolsas de doutorado (Proc.97/11302-3) e pós-doutorado (Proc. 03/04509-3).

\section{REFERÊNCIAS BIBLIOGRÁFICAS}

Acero, P. A. 2003. Family Ariidae. In: Carpenter, K. E. ed. The living marine resources of the Western Central Atlantic. Volume 2: Bony fishes part 1 (Acipenseridae to Grammatidae). FAO species identification guide for fishery purposes and American Society of Ichthyologist and Herpetologists Special Publication No. 5. Western Central Atlantic. V. 2. FAO. p.831-852.

Barletta, M.; Barletta-Bergan, A.; Saint-Paul, U. \& Hubold, G. 2003. Seasonal changes in density, biomass, and diversity of estuarine fishes in tidal mangrove creeks of the lower Caeté Estuary (northern Brazilian coast, east Amazon). Marine Ecology Progress Series 256:217-228.

Boeseman, M. 1972. Notes on South American catfishes, including remarks on Valenciennes and Bleeker types in the Leiden Museum. Zoölogische Mededelingen 47(23):293-320.

Boulenger, G. A. 1897. On a collection of fishes from the island of Marajo, Brazil. Annals and Magazine of Natural History (Series 6) 20(117):294-299.

Cuvier, G. \& Valenciennes, A. 1840. Histoire naturelle des poissons. Tome quinzième. Suite du livre dix-septième. Siluroïdes. Paris. V. Levrault, Strasbourg. 540p.

Diaz de A. A. \& Bashirullah, A. K. M. 1984. Estudios biologicos del bagre guinche, Cathorops spixii (Fam. Ariidae) en el Golfo de Cariaco, Venezuela. 1. Habitos alimentares de Juveniles. 
Boletin del Instituto Oceanográfico de la Universidad de Oriente 23(1-2):195-200.

EigenmanN, C. H. 1912. The freshwater fishes of British Guiana, including a study of the ecological grouping of species and the relation of the fauna of the plateau to that of the lowlands. Memoirs of the Carnegie Museum 5:129-147.

Eigenmann, C. H. \& Eigenmann, R. S. 1888. Preliminary notes on South American Nematognathi. I. Proceedings of the California Academy of Sciences (Series 2) 1(2):119-172.

Eigenmann, C. H. \& Eigenmann, R. S. 1890. A revision of the South American Nematognathi or cat-fishes. Occasional Papers California Academy of Sciences 1:11-508.

Etchevers, S. L. 1978. Contribution to the biology of the sea catfish, Arius spixii (Agassiz) (Pisces, Ariidae), south of Margarita Island, Venezuela. Bulletin of Marine Science 28:381-385.

Günther, A. 1864. Catalogue of the fishes in the British Museum. Volume 5. Catalogue of the Physostomi, containing the families Siluridae, Characinidae, Haplochitonidae, Sternoptychidae, Scopelidae, Stomiatidae in the collection of the British Museum. London, Trustees. 455p.

Jordan, D. S. \& Evermann, B. W. 1898. The fishes of North and Middle America: a descriptive catalogue of the species of fish-like vertebrates found in the waters of North America north of the Isthmus of Panama. Part III. Bulletin United States National Museum 47:2183-3136.

Lara-Dominguez, A. L.; Yánez-Arancibia, A. \& Amezcura Linares, F. 1982. Biologia y ecologia del bagre Arius melanopus Günther en la Laguna de Términos, sur del Golfo de México (Pisces: Ariidae). Anales del Centro de Ciencias del Mar y Limnologia Universidad Nacional Autónoma de México 8(1):267-304
Marceniuk, A. P. 2005. Chave para identificação das espécies de bagres marinhos (Siluriformes, Ariidae) da costa brasileira. Boletim do Instituto de Pesca São Paulo 31(2):89-101.

Marceniuk, A. P. \& Ferraris, JR. C. J. 2003. Family Ariidae (Sea catfishes). In: Reis, R. E., Kullander, S. O. \& Ferraris, JR. C. J. eds. Check list of the freshwater fishes of South and Central America. Porto Alegre, EDIPUCRS. 742p.

Marceniuk, A. P. \& Menezes, N. A. 2003. Família Ariidae. In: Menezes, N. A., Buckup, P. A., de Figueiredo, J. L. \& de Moura, R. L. eds. Catálogo das espécies de peixes marinhos do Brasil. São Paulo, MZUSP. 160p.

Meek, S. E. \& Hildebrand, S. F. 1923. The marine fishes of Panama. Part I. Field Museum Natural History Publications Zoological Series 15(215):1-330.

Mello, S. C. \& Teixeira, R. L. 1992. Distribuição, reprodução e alimentação de Cathorops spixii e Arius rugispinis (Pisces, Ariidae) do complexo Mundaú Manguabá, Maceió, AL. Revista Brasileira de Biologia 52(1):169-180.

MirandA-Ribeiro, A. DE. 1911. Fauna brasiliense. Peixes. Tomo IV (A) [Eleutherobranchios Aspirophoros]. Arquivos do Museu Nacional do Rio de Janeiro 16(4):1-504.

Mishima, M. \& TANJI, S. 1981. Distribuição geográfica dos bagres marinhos (Osteichthys, Ariidae) no complexo estuarino lagunar de Cananéia $\left(25^{\circ} \mathrm{S}, 48^{\circ} \mathrm{W}\right)$. Boletim do Instituto de Pesca-São Paulo 8:157-172.

Puyo, J. 1949. Faune de I’ Empire Français, XII. Poissons de la Guyane Française. Paris, Office de la Recherche Scientifique Outre-Mer. 280p.

TAYlor, W. R. \& Menezes, N. A. 1977. Ariidae: Sea Catfishes. In: FISCHER, W. ed. FAO species identification sheets fishery purpose. Western Central Atlantic (fishing area 31). v. 1-7. Rome, Food and Agriculture Organisation. p.1-37.

Recebido em outubro de 2005. Aceito em abril de 2007. ISSN 0073-4721

Artigo disponível em: www.scielo.br/isz 